\title{
Recursos do orçamento público federal destinados ao meio rural: dinâmica das contas brasileiras entre 2000 e 2017
}

\author{
Budget allocation for rural areas: dynamics of Brazilian federal \\ expenditures from 2000 to 2017
}

\author{
Leonardo Ferraz Xavier ${ }^{1}$ (1) \\ 'Programa de Pós-graduação em Administração e Desenvolvimento Rural, Departamento de Economia, Universidade Federal
} Rural de Pernambuco (UFRPE), Recife (PE), Brasil. E-mail: leonardoferraz@gmail.com

\begin{abstract}
Como citar: Xavier, L. F. (2021). Recursos do orçamento público federal destinados ao meio rural: dinâmica das contas brasileiras entre 2000 e 2017. Revista de Economia e Sociologia Rural, 59(2), e217682. https://doi.org/10.1590/18069479.2021 .217682
\end{abstract}

\begin{abstract}
Resumo: Com a vigência da Emenda Constitucional n 95/2016, que limita os gastos públicos federais por 20 anos, eleva-se a concorrência pela utilização desses recursos entre seus reivindicantes. Por meio do Painel do Orçamento Federal, este artigo descreve a dinâmica de aplicação dos gastos federais desde 2000, especialmente quanto aos recursos voltados ao meio rural. Para tanto, os gastos federais são discriminados entre grupos de função e despesa, unidades orçamentárias, programas e ações específicas. A análise mostra que os gastos destinados ao meio rural, já entendidos como limitados, têm perdido espaço na distribuição do orçamento, exceto quando se consideram os gastos com beneficiários rurais da Previdência Social. O panorama reforça a necessidade de reversão desse comportamento, tornando-o coerente com a relevância socioeconômica do meio rural brasileiro.
\end{abstract}

Palavras-chave: Orçamento Público Federal, meio rural, Brasil.

\begin{abstract}
The 95th Constitutional Amendment of Brazil, which limits federal public spending for twenty years starting in 2016, increases the competition for the use of these values among its claimants. Through the National Budget Panel, this study describes the dynamics of federal expenditures since 2000, especially on resources directed to rural areas. For this purpose, federal spending is separated into function and expense groups, budget units, programs, and specific actions. The analysis shows that expenditures directed to rural areas, considered already low, have lost space in the budget distribution, except for expenses with rural Social Security beneficiaries. This view reinforces the need to reverse the situation to be consistent with the socioeconomic relevance of the Brazilian rural area.
\end{abstract}

Keywords: National Budget, rural area, Brazil.

\section{INTRODUÇÃO}

O presente artigo reúne dados do Painel do Orçamento Federal (Brasil, 2018a) quanto à composição dos gastos anuais liquidados, segundo grupos de despesa e função, avaliados para o período entre 2000 e 2017. Especificamente, contempla-se a dinâmica dos gastos alocados pelo governo federal ao meio rural, com vistas a comparar sua evolução em relação a outros setores. Trata-se de um trabalho voltado a interessados em dados compilados, úteis para uma melhor concepção sobre a política governamental aplicada ao meio rural nos últimos anos.

O orçamento da União pode ser dividido em grupos gerais de função e despesa, conforme definido pelo Ministério do Planejamento. Quanto aos grupos de função, eles são classificados em 28 itens, tais como: 09-Previdência Social; 10-Saúde; 12-Educação; 20Agricultura; e 22-Indústria. Por sua vez, com respeito aos grupos de despesa, a classificação 
disponível no Painel do Orçamento é dividida em seis itens: 01-Pessoal e Encargos Sociais; 02Juros e Encargos da Dívida; 03-Outras Despesas Correntes; 04-Investimentos; 05-Inversões Financeiras; e 06-Amortização da Dívida. Particularidades relativas a cada um desses grupos serão apresentadas na seção Metodologia.

Abordando-se cada grupo orçamentário, procura-se então observar como o governo federal, no período em análise, tem destinado recursos ao meio rural brasileiro. Como limitação, porém, destaca-se que a análise contém um grau de agregação que não permite avaliar a distribuição geográfica das aplicações, bem como desconsidera as realizações de governos estaduais e municipais com seus recursos geridos.

Com vistas a dar um direcionamento objetivo aos resultados e às reflexões do artigo, este foi organizado em seis seções, incluindo esta breve Introdução. A seguir, em Metodologia, descrevem-se o desmembramento do orçamento federal e os detalhes relativos à produção dos dados apresentados no trabalho. Em seguida, a seção Panorama Orçamentário traz uma visão geral dos gastos federais, com sua evolução discriminada entre grupos de função e despesa. Posteriormente, em Panorama por Grupos de Despesa, adentrase nos grupos de despesa e na distribuição desses gastos entre diversas funções. Por sua vez, em Orçamento Voltado ao Meio Rural, principal foco deste artigo, três subseções descrevem o comportamento dos recursos federais destinados especificamente ao meio rural, segundo diferentes tipologias de gastos. Por fim, a seção Conclusão procura lançar reflexões pertinentes ao tema desenvolvido, enfatizando-se a importância de um constante acompanhamento da dinâmica de gastos federais particularmente destinados ao meio rural.

\section{METODOLOGIA}

O Sistema Integrado de Planejamento e Orçamento (SIOP) foi desenvolvido a partir de 2009 pela Secretaria de Orçamento Federal do Ministério do Planejamento, integrando tecnologias mais adequadas a desenvolver e a manter processos informatizados que viessem a suportar o planejamento e o orçamento do governo federal (Brasil, 2018b). Disposto em módulos, o SIOP permite fazer registros habituais e efetuar consultas e análises. Entre suas ferramentas, o Painel do Orçamento Federal (Brasil, 2018a) foi essencial à realização deste artigo. Tal interface permite coletar informações da Lei Orçamentária Anual (LOA) e de sua execução, de forma que toda pessoa com acesso à internet pode consultar dados atualizados e séries históricas, sem a exigência de quaisquer autenticações, autorizações ou cadastros.

O horizonte temporal dos dados disponíveis no Painel do Orçamento abrange o período posterior a 2000. Contudo, ressalta-se que certos gastos tiveram suas tipologias alteradas ao longo do tempo ou mesmo foram manejadas entre diferentes grupos de funções e despesas. Um dos esforços do presente artigo foi justamente identificar tais ajustes e analisar o comportamento dos gastos, minimizando-se as distorções decorrentes das mudanças nos critérios de classificação ao longo dos anos. Além disso, como o objetivo do estudo volta-se à compreensão dos gastos públicos federais especificamente destinados ao meio rural, foi indispensável estabelecer associações entre as nomenclaturas disponíveis e o enfoque do estudo, procurando-se, inclusive, processar contas em níveis menos agregados possíveis.

O Painel do Orçamento permite consultar os gastos federais segundo diversos detalhamentos, como valores liquidados, empenhados ou pagos. Neste estudo, preferiu-se considerar apenas os valores liquidados (quando o serviço é finalmente executado), em vez de valores empenhados (quando o serviço é contratado) ou pagos (quando o prestador do serviço de fato recebe pelo serviço contratado). Tal opção se justifica porque valores empenhados nem sempre são liquidados, em razão, por exemplo, da não execução de um serviço. Por sua vez, é possível que o pagamento de um serviço executado não seja feito imediatamente, dependendo de provisões ou do próprio contrato estabelecido com o fornecedor. Dessa forma, é possível que um serviço executado em certo ano, ou seja, com valor liquidado no ano de execução, tenha o valor pago registrado apenas no ano seguinte. Essas observações motivaram a consideração apenas dos valores liquidados no presente estudo.

Outras formas de detalhamento disponíveis no Painel do Orçamento remetem a diferentes órgãos orçamentários (como Câmara, Senado, Justiça Federal, Ministérios etc.), 
unidades orçamentárias (como certa Secretaria de um Ministério) ou mesmo programas (como uma política efetuada por determinada unidade orçamentária) e ações específicas (algo realizado para alcançar o objetivo de certo programa). Contudo, os principais detalhamentos considerados neste artigo referem-se aos grupos de função e despesa, tipologias que seguem as definições descritas no Manual Técnico de Orçamento (Brasil, 2018c).

Quanto aos grupos de função, a classificação disponibilizada identifica 28 itens: 01Legislativa; 02-Judiciária; 03-Essencial à Justiça; 04-Administração; 05-Defesa Nacional; 06Segurança Pública; 07-Relações Exteriores; 08-Assistência Social; 09-Previdência Social; 10 Saúde; 11-Trabalho; 12-Educação; 13-Cultura; 14-Direitos da Cidadania; 15-Urbanismo; 16Habitação; 17-Saneamento; 18-Gestão Ambiental; 19-Ciência e Tecnologia; 20-Agricultura; 21 Organização Agrária; 22-Indústria; 23-Comércio e Serviços; 24-Comunicações; 25-Energia; 26Transporte; 27-Desporto e Lazer; e 28-Encargos Especiais. Salienta-se que os órgãos orçamentários, a exemplo de cada um dos Ministérios que compõem o Executivo, podem apresentar gastos identificados em mais de um grupo de função. Além disso, dada a amplitude de nomenclaturas, preferiu-se agregar certas funções ${ }^{1}$. Tais ajustes se fizeram oportunos por facilitar a visualização de gráficos e enfocar a análise sobre o essencial, ou seja, o direcionamento de recursos públicos ao meio rural brasileiro.

Por sua vez, com respeito aos grupos de despesa, o Painel do Orçamento Federal classifica seis itens: 01-Pessoal e Encargos Sociais; 02-Juros e Encargos da Dívida; 03-Outras Despesas Correntes; 04-Investimentos; 05-Inversões Financeiras; e 06-Amortização da Dívida. Segundo o Manual Técnico de Orçamento (Brasil, 2018c), pode-se interpretar que o grupo 01Pessoal e Encargos Sociais compreende basicamente responsabilidades da União com pessoal ativo e inativo, bem como pensionistas, inclusive encargos sociais e pessoal ativo de estatais. Quanto o grupo 02-Juros e Encargos da Dívida, ele reúne os pagamentos de juros, comissões e outros encargos das operações de crédito contratadas e da dívida pública mobiliária. No grupo 03-Outras Despesas Correntes, há responsabilidades com o Regime Geral de Previdência Social, com a assistência social (Benefício de Prestação Continuada, Bolsa Família etc.), com a proteção do trabalhador (seguro-desemprego, abono salarial etc.), além do custeio de suas funções. No grupo 04-Investimentos, estão gastos com obras e aquisição de imóveis, instalações, equipamentos, material permanente e softwares. Quanto ao grupo 05-Inversões Financeiras, encontram-se gastos com aquisição de bens já em utilização, produtos para revenda, títulos do capital de entidades, além de financiamentos. Por fim, o grupo 06-Amortização da Dívida refere-se à gradual devolução do principal da dívida pública, inclusive das atualizações monetária e cambial. Por conveniência, os grupos 02-Juros e Encargos da Dívida e 06-Amortização da Dívida foram tratados em conjunto².

As tipologias aqui descritas serviram de base para o presente estudo. Inicialmente, pretende-se dar uma visão geral dos gastos federais, com sua evolução discriminada entre grupos de função e despesa. Posteriormente, traz-se um olhar sobre cada grupo de despesa, discriminando-se a distribuição desses gastos entre as diversas funções estudadas. Em seguida, adentra-se no comportamento dos recursos destinados especificamente ao meio rural, observando-se as seguintes etapas: i) um olhar específico sobre as funções 20-Agricultura e 21-Organização Agrária, que são diretamente identificadas com o meio rural, discriminando-se seus gastos por grupos de despesa e por unidades orçamentárias; ii) análise dos gastos das funções 20-Agricultura e 21-Organização Agrária segundo programas e ações específicas; e iii) agregação dos gastos associados ao meio rural, mas não identificados com as funções 20-Agricultura e 21-Organização Agrária.

1i) 02-Judiciária e 03-Essencial à Justiça; ii) 08-Assistência Social e 14-Direitos da Cidadania; iii) 12-Educação, 13-Cultura, 19-Ciência/Tecnologia e 27-Desporto/Lazer; iv) 15-Urbanismo, 16-Habitação, 17-Saneamento e 26-Transporte; v) 20Agricultura e 21-Organização Agrária; e vi) 22-Indústria e 23-Comércio/Serviços.

2Já que esses gastos se referem unicamente à função 28-Encargos Especiais, associada ao financiamento dos gastos públicos e à rolagem de sua dívida. 
Nessa última etapa, procurou-se identificar ações específicas cujas descrições contivessem termos relacionados ao meio rural ${ }^{3}$.

As análises envolveram os anos de 2000 a 2017, visto que os valores liquidados referentes a 2018 ainda não foram consolidados. Salienta-se que a dinâmica da composição dos gastos foi avaliada em termos reais, corrigindo-se os valores para preços de dezembro de 2017, de acordo com o Índice de Preços ao Consumidor Amplo (IPCA), indexador oficial do país (Instituto Brasileiro de Geografia e Estatística, 2018). Tal procedimento busca considerar a variação real dos gastos, a qual será apresentada em taxa de crescimento equivalente anual relativa ao primeiro ano da série, calculada como $g=\left(G_{2017} / G_{2000}\right)^{l /(2017-2000)}-1$, em que $g$ é a taxa de crescimento equivalente anual entre 2000 e 2017, e $G_{t}$ diz respeito ao gasto real analisado no ano $t$, seja em determinada função, grupo de despesa, órgão orçamentário, programa ou ação específica.

\section{PANORAMA ORÇAMENTÁRIO}

Em termos reais, o total de gastos liquidados no orçamento da União cresceu de $\mathrm{R} \$ 1,80$ trilhão em 2000 para $\mathrm{R} \$ 2,51$ trilhões em 2017 , um ritmo de 1,96\% a.a. ${ }^{4} \mathrm{Em} 2017$, o grupo de despesas 03-Outras Despesas Correntes foi o maior contribuinte desse montante, com $R \$ 1,13$ trilhão e ritmo de $5,63 \%$ a.a. em relação a 2000 , bem superior à evolução do orçamento geral. Nesse grupo, destaca-se que $\mathrm{R} \$ 550,9$ bilhões se referem somente à função 09-Previdência Social ${ }^{5}$, enquanto $R \$ 268,1$ bilhões dizem respeito à função 28-Encargos Especiais ${ }^{6}$.

Os grupos 06-Amortização da Dívida e 02-Juros e Encargos da Dívida também se destacaram, somando R\$986,1 bilhões em 2017 (-0,75\% a.a. em comparação a 2000). Salienta-se que, apesar do peso desses dois grupos no orçamento da União, estes são particularmente cobertos por operações financeiras de rolagem da dívida. Com efeito, da receita líquida do governo (arrecadação menos transferências a estados e municípios), faz-se o pagamento de gastos primários (previdência, investimento, pessoal, custeio etc.), e, havendo sobras (superávit primário), tais recursos são aproveitados para abater o serviço da dívida. Assim, não havendo superávit primário ou não sendo este suficiente para pagar os juros e encargos da dívida a liquidar naquele ano, o governo recorre a novas dívidas, por meio do Tesouro Nacional, via operações de refinanciamento ou emissão de novos títulos ${ }^{7}$. Obviamente, com menor taxa de juros na rolagem da dívida e esforço para obter superávit primário, é possível reduzir a dívida pública. Do contrário, a tendência é que essa dívida cresça, piorando a nota de risco do país avaliada por agências de classificação, o que reforça o movimento de acréscimo na taxa de juros para atrair investidores que se interessem em adquirir novos títulos ${ }^{8}$.

Quanto aos demais grupos, registraram-se: 01-Pessoal e Encargos Sociais, com $\mathrm{R} \$ 304,1$ bilhões $^{9}$ em 2017 e ritmo de 3,48\% a.a. em relação a 2000; 05-Inversões

\footnotetext{
${ }^{3}$ Como "rural", "rurais", "agrári", "agrícol", "agricult", "agropec", "agroneg", "agroind", "pecuár" e "pecuar". Os termos truncados objetivaram localizar ações que contivessem, por exemplo, expressões como "agrária" ou "agrário", "agrárias" ou "agrários", entre outras.

${ }^{4} \mathrm{Em}$ análise sobre dois períodos distintos, Abreu \& Lima (2018) detectaram que o aumento dos gastos públicos teve efeitos positivos sobre o PIB brasileiro no primeiro intervalo de tempo (1999-2007). Contudo, no segundo intervalo analisado (20092016), os autores sugerem que o efeito se deu de forma inversa.

${ }^{5}$ Em 2017, desse total, $R \$ 428,4$ bilhões referem-se a benefícios previdenciários urbanos, enquanto $R \$ 117,4$ bilhões são de benefícios rurais. O peso desses gastos impositivos decorre de falhas no sistema previdenciário, cujo diagnóstico foi abordado por Giambiagi et al. (2018). Ainda, segundo Gobetti \& Orair (2017), a tendência de crescimento desses gastos é um exemplo de problema estrutural que tem comprometido o orçamento público.

${ }^{6}$ Desse montante registrado em 2017, $R \$ 218$,2 bilhões correspondem a transferências a estados e municípios, sobretudo o Fundo de Participação dos Municípios (FPM), com R $\$ 75,3$ bilhões, o Fundo de Participação dos Estados e do Distrito Federal (FPE), com $R \$ 64,4$ bilhões, e o Fundo de Manutenção e Desenvolvimento da Educação Básica e de Valorização dos Profissionais da Educação (FUNDEB), com R $\$ 34,5$ bilhões.

${ }^{7}$ Títulos compreendem quase a totalidade da dívida pública federal.

${ }^{8}$ Apesar de auxiliar na rolagem da dívida e no financiamento de déficits públicos, o aumento da taxa de juros acaba absorvendo a poupança privada, que, em vez de financiar a dívida pública, poderia sustentar investimentos em negócios, tecnologia etc. Esses são importantes motivos que justificam o controle da dívida pública.

${ }^{9}$ Desse total, $\mathrm{R} \$ 104,5$ bilhões referem-se somente à função 09-Previdência Social.
} 
Financeiras, com R\$ 63,6 bilhões $^{10}$ e 3,87\% a.a.; e 04-Investimentos, com $\mathrm{R} \$ 18,9$ bilhões $^{11}$ e $-2,59 \%$ a.a. Detalhes associados a cada um desses grupos serão apresentados na seção seguinte, intitulada Panorama por Grupo de Despesa. A seguir, a Figura 1 ilustra o comportamento geral desses gastos.

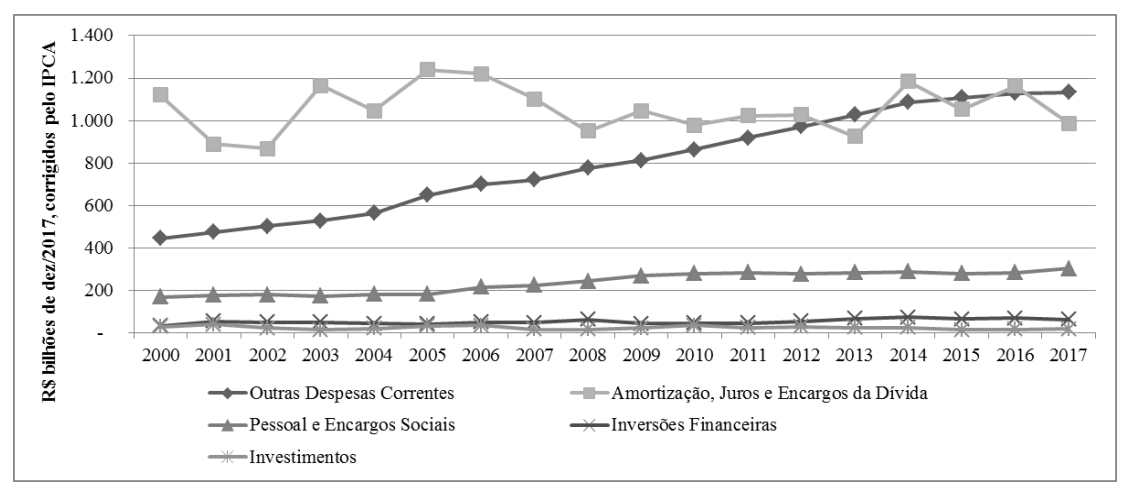

Figura 1. Gastos liquidados por grupos de despesa no Orçamento Federal. Fonte: Brasil (2018a), Instituto Brasileiro de Geografia e Estatística (2018).

Por sua vez, quanto à distribuição dos gastos de acordo com funções, dos $\mathrm{R} \$ 2,51$ trilhões liquidados em 2017, a função 28-Encargos Especiais respondeu por $\mathrm{R} \$ 1,29$ trilhão. Em 2000, esse valor correspondia a $\mathrm{R} \$ 1,27$ trilhão (representando um leve acréscimo real de 0,10\% a.a.). Porém, mesmo descontando os gastos nos grupos de Amortização, Juros e Encargos da Dívida, a função de Encargos Especiais somou expressivos R $\$ 305,6$ bilhões em 2017 ${ }^{12}$, com crescimento real de 4,33\% a.a. em relação a 2000.

Além da função de Encargos Especiais, outros importantes contribuintes referem-se à Previdência Social ( $R \$$ 655,5 bilhões $^{13}$ em 2017 e expressivo crescimento real de 5,29\% a.a. em relação a 2000), Educação, Cultura, Ciência/Tecnologia e Desporto/Lazer (R $\$ 109,7$ bilhões ${ }^{14}$ em 2017 e ritmo de 6,80\% a.a.), Saúde (R\$103,2 bilhões e 3,33\% a.a.), Assistência Social e Direitos da Cidadania (R\$ 85,5 bilhões e 11,16\% a.a.), Trabalho (R\$ 69,9 bilhões e 8,22\% a.a.), Defesa Nacional ( $R \$ 63,6$ bilhões e 4,31\% a.a.) e Judiciário e Essencial à Justiça (R\$ 40,4 bilhões e 3,95\% a.a.) ${ }^{15}$. Por sua vez, as demais funções somadas registraram gastos de $\mathrm{R} \$ 86$ bilhões em 2017 e ritmo de 0,52\% a.a. em relação a 2000.

As Figuras 2, 3 e 4 ilustram a dinâmica desses gastos, separando as funções em estratos de maior e menor participação no montante do orçamento da União. Salienta-se que, para as funções de Agricultura e Organização Agrária, os gastos de R \$ 18 bilhões em 2000 caíram para $\mathrm{R} \$ 17,3$ bilhões em 2017 (queda real de 0,24\% a.a. ${ }^{16}$ ). Essa variação ficou aquém do crescimento de $0,10 \%$ a.a. nos gastos gerais da União, bem como da média calculada para o estrato de funções de menor participação, descritas na Figura 4, que alcançou 0,52\% a.a. Com

\footnotetext{
${ }^{10}$ Desse total, $R \$ 20,5$ bilhões referem-se às funções 12-Educação, 13-Cultura, 19-Ciência/Tecnologia e 27-Desporto/Lazer, enquanto $R \$ 18,6$ bilhões associam-se à função 28 -Encargos Especiais, e $R \$ 15,7$ bilhões, à função 11-Trabalho.

${ }^{11} \mathrm{Em}$ que $\mathrm{R} \$ 6,9$ bilhões se concentram na soma das funções 15-Urbanismo, 16-Habitação, 17-Saneamento e 26-Transporte, enquanto $R \$ 6,1$ bilhões dizem respeito à função 05-Defesa Nacional.

${ }^{12}$ Desse total, $R \$ 268,1$ bilhões referem-se somente à função 03-Outras Despesas Correntes, como antes relatado. ${ }^{13}$ Desse total, como já colocado, $\mathrm{R} \$ 550,9$ bilhões estão no grupo 03-Outras Despesas Correntes, enquanto $\mathrm{R} \$ 104,5$ bilhões se encontram em 01-Pessoal e Encargos Sociais, associados aos beneficiários do funcionalismo público.

${ }^{14}$ Desse total, $R \$ 46,8$ bilhões referem-se somente ao grupo 01-Pessoal e Encargos Sociais, enquanto $R \$ 40,7$ bilhões dizem respeito a 03-Outras Despesas Correntes, e R $\$ 20,5$ bilhões, a 05-Inversões Financeiras.

${ }^{15}$ Nas funções de Saúde e Assistência Social/Direitos da Cidadania, os gastos se referem, principalmente, ao grupo 03Outras Despesas Correntes (respectivamente, $R \$ 92,2$ bilhões e $R \$ 84,6$ bilhões). Por sua vez, nas funções de Trabalho, Defesa Nacional e Judiciário/Essencial à Justiça, destaca-se o grupo 01-Pessoal e Encargos Sociais (respectivamente, $\mathrm{R} \$ 54,1$ bilhões, $\mathrm{R} \$ 47,8$ bilhões e $\mathrm{R} \$ 31$ bilhões).

${ }^{16} \mathrm{Tal}$ comportamento parece incompatível diante do considerável crescimento apresentado pela produção agropecuária brasileira nas últimas décadas. A partir de dados do Centro de Estudos Avançados em Economia Aplicada (CEPEA), pode-se calcular que essa produção cresceu a um ritmo de 3,43\% a.a. entre 2000 e 2017, enquanto sua participação no PIB brasileiro evoluiu a uma taxa de 1,04\% a.a. no mesmo intervalo (Universidade de São Paulo, 2018).
} 
efeito, a queda de $0,24 \%$ a.a. só não ficou abaixo da dinâmica nas funções de Gestão Ambiental (-0,40\% a.a.), Urbanismo, Saneamento, Habitação e Transporte $(-0,71 \%$ a.a.) e Indústria e Comércio/Serviços (-2,33\% a.a.).

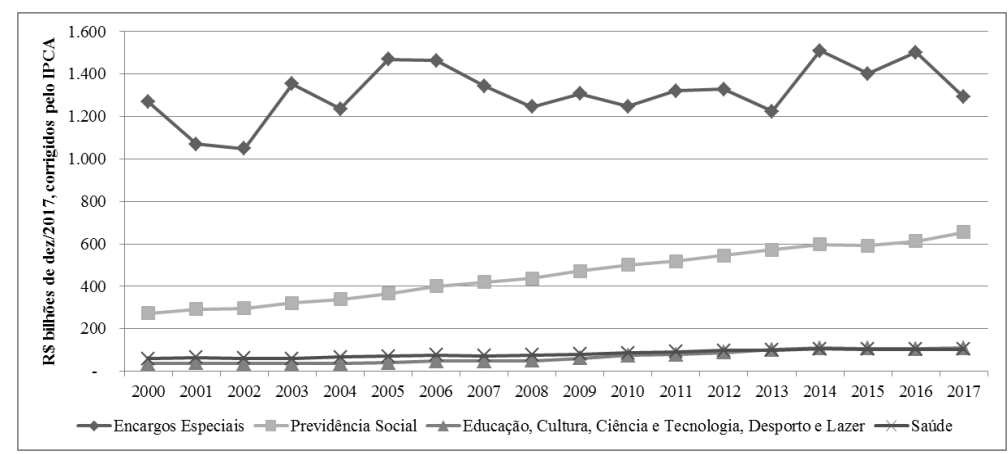

Figura 2. Gastos liquidados no Orçamento Federal, segundo funções de maior participação. Fonte: Brasil (2018a), Instituto Brasileiro de Geografia e Estatística (2018).

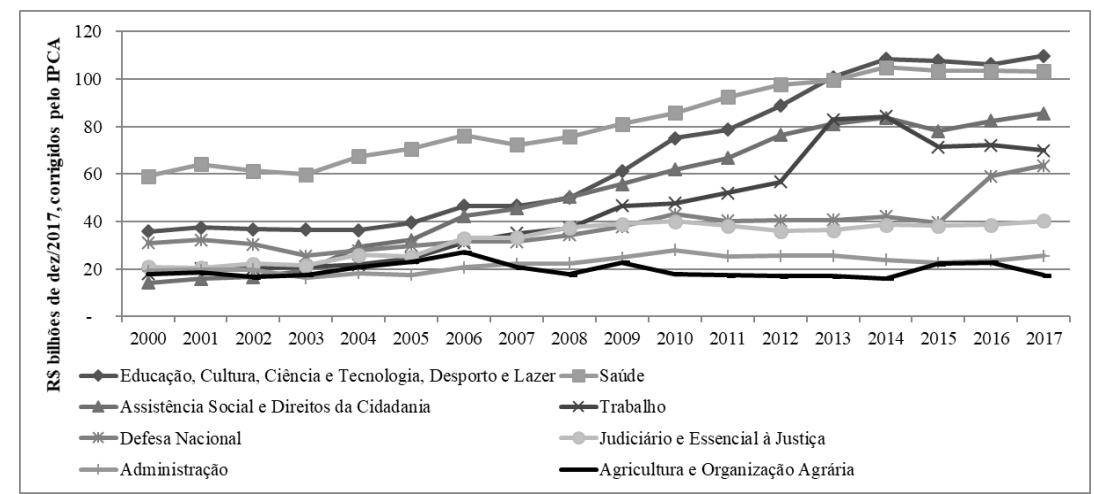

Figura 3. Gastos liquidados no Orçamento Federal, segundo funções de maior participação (exceto as funções 28-Encargos Especiais e 09-Previdência Social). Fonte: Brasil (2018a), Instituto Brasileiro de Geografia e Estatística (2018).

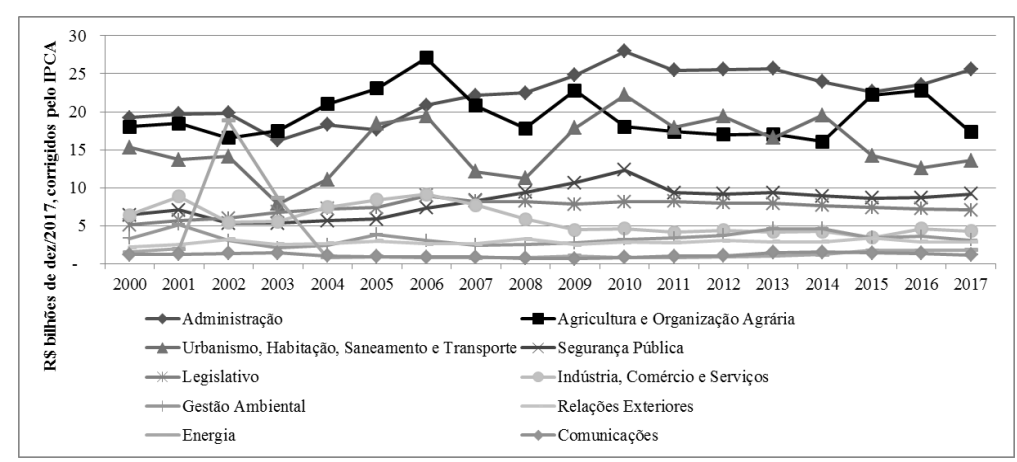

Figura 4. Gastos liquidados no Orçamento Federal, segundo funções de menor participação. Fonte: Brasil (2018a), Instituto Brasileiro de Geografia e Estatística (2018).

\section{PANORAMA POR GRUPO DE DESPESA}

Nesta seção, os gastos federais são analisados em cada grupo de despesa, discriminando-se seus valores entre as várias funções aqui estudadas, com ênfase na evolução apresentada pelas funções 20-Agricultura e 21-Organização Agrária. As informações encontram-se compiladas na Tabela 1, que traz os gastos relativos ao ano de 2017 e a taxa de crescimento equivalente anual relativa a 2000, discriminando-se cada grupo de despesa em suas colunas. Cada linha da Tabela, por sua vez, expõe grupos de função, ordenados segundo suas participações no gasto total. Células mais escuras ressaltam os maiores gastos em cada 
grupo de despesa. Ainda, em negrito, destacam-se os gastos nas funções de Agricultura e Organização Agrária.

Tabela 1. Gastos liquidados no orçamento federal em 2017, segundo grupos de função e despesa (valores em $\mathrm{R} \$$ bilhões e taxa de crescimento equivalente em \% a.a. em relação a 2000).

\begin{tabular}{|c|c|c|c|c|c|c|c|c|c|c|}
\hline \multirow{3}{*}{ Funções } & \multicolumn{8}{|c|}{ Grupos de despesa ${ }^{(i)}$} & & \\
\hline & \multicolumn{2}{|c|}{$\begin{array}{l}\text { 01-Pessoal e } \\
\text { Enc. Sociais }\end{array}$} & \multicolumn{2}{|c|}{$\begin{array}{l}\text { 03-Outras } \\
\text { Desp. } \\
\text { Correntes }\end{array}$} & \multicolumn{2}{|c|}{$\begin{array}{c}\text { 04- } \\
\text { Investimento } \\
\mathrm{s} \\
\end{array}$} & \multicolumn{2}{|c|}{$\begin{array}{l}\text { 05-Inversões } \\
\text { Financeiras }\end{array}$} & \multicolumn{2}{|c|}{ Total (ii) } \\
\hline & R\$ bi & $\%$ a.a. & R\$ bi & $\%$ a.a. & R\$ bi & $\%$ a.a. & R\$ bi & $\%$ a.a. & $\mathbf{R} \$ \mathbf{b i}$ & $\%$ a.a. \\
\hline $\begin{array}{l}\text { Encargos } \\
\text { Especiais }\end{array}$ & 18,9 & 4,89 & 268,1 & 4,70 & 0,03 & $-10,74$ & 18,6 & 0,45 & $1.291,7$ & 0,10 \\
\hline Previdência Social & 104,5 & 1,62 & 550,9 & 6,36 & 0,01 & $-11,26$ & - & - & 655,5 & 5,29 \\
\hline $\begin{array}{c}\text { Educação, } \\
\text { Cultura, } \\
\text { Ciência/Tecnol. e } \\
\text { Desporto/Lazer }\end{array}$ & 46,8 & 7,10 & 40,7 & 5,83 & 1,80 & $-2,82$ & 20,5 & 12,35 & 109,7 & 6,80 \\
\hline Saúde (iii) & 10,0 & 1,78 & 92,2 & 3,92 & 0,95 & $-7,75$ & 0,0 & - & 103,2 & 3,33 \\
\hline $\begin{array}{l}\text { Assist. Social e } \\
\text { Direitos/ } \\
\text { Cidadania }\end{array}$ & 0,4 & $-0,91$ & 84,6 & 11,61 & 0,52 & $-0,98$ & - & - & 85,5 & 11,16 \\
\hline Trabalho (iii) & 0,1 & $-17,72$ & 54,1 & 7,16 & 0,03 & $-8,66$ & 15,7 & - & 69,9 & 8,22 \\
\hline Defesa Nacional & 47,8 & 5,72 & 9,3 & 1,35 & 6,06 & 1,08 & 0,5 & 55,00 & 63,6 & 4,31 \\
\hline $\begin{array}{c}\text { Judiciário e } \\
\text { Essencial à Justiça }\end{array}$ & 31,0 & 3,61 & 8,4 & 5,88 & 0,70 & $-0,12$ & 0,2 & 21,21 & 40,4 & 3,95 \\
\hline Administração & 19,4 & 4,19 & 5,6 & $-1,44$ & 0,31 & $-2,09$ & 0,2 & $-13,46$ & 25,5 & 1,68 \\
\hline $\begin{array}{c}\text { Agricultura e } \\
\text { Organiz. Agrária }\end{array}$ & 6,1 & 4,29 & 6,8 & 1,99 & 0,19 & $-12,48$ & 4,2 & $-3,93$ & 17,3 & $-0,24$ \\
\hline $\begin{array}{c}\text { Urbanismo, } \\
\text { Habit., Saneam. e } \\
\text { Transp. }\end{array}$ & 2,3 & 6,36 & 2,0 & $-4,96$ & 6,92 & $-1,50$ & 2,3 & 7,17 & 13,6 & $-0,71$ \\
\hline $\begin{array}{l}\text { Segurança } \\
\text { Pública }\end{array}$ & 6,5 & 4,48 & 2,5 & 3,04 & 0,18 & $-12,75$ & - & - & 9,2 & 2,15 \\
\hline Legislativo & 5,5 & 2,01 & 1,6 & 2,03 & 0,05 & $-4,93$ & - & - & 7,1 & 1,91 \\
\hline $\begin{array}{c}\text { Indústria e } \\
\text { Com./Serviços }\end{array}$ & 1,3 & 10,16 & 1,7 & $-3,97$ & 0,03 & $-14,50$ & 1,2 & $-3,50$ & 4,3 & $-2,33$ \\
\hline Gestão Ambiental & 1,2 & 5,85 & 0,9 & 0,66 & 1,03 & $-4,07$ & 0,0 & 3,13 & 3,1 & $-0,40$ \\
\hline $\begin{array}{l}\text { Relações } \\
\text { Exteriores }\end{array}$ & 1,0 & 0,96 & 1,9 & 2,18 & 0,02 & $-2,09$ & - & - & 2,9 & 1,68 \\
\hline Energia (iii) & 0,6 & 0,57 & 1,2 & 2,00 & 0,01 & $-16,52$ & 0,0 & - & 1,8 & 0,97 \\
\hline Comunicações & 0,8 & 7,52 & 0,2 & $-7,27$ & 0,01 & $-15,17$ & 0,2 & 10,87 & 1,2 & $-0,04$ \\
\hline Total & 304,1 & 3,48 & $1.132,9$ & 5,63 & 18,87 & $-2,59$ & 63,6 & 3,87 & $2.505,6$ & 1,96 \\
\hline
\end{tabular}

Notas: (i) Os grupos 02-Juros e Encargos da Dívida e 06-Amortização da Dívida foram omitidos, já que só se referem à função de Encargos Especiais (esses grupos somaram $R \$ 986,1$ bilhões em 2017 e ritmo de -0,75\% a.a. em relação a 2000); (ii) Como consequência da nota anterior, tanto na linha que trata da função de Encargos Especiais quanto na última linha da tabela, os valores em $\mathrm{R} \$$ bilhões dispostos na coluna "Total” não equivalem à soma das outras colunas; (iii) No grupo de Inversões Financeiras, as funções de Saúde, Trabalho e Energia não contavam com registros no primeiro ano da série, o que impediu calcular as taxas de crescimento nesses casos. Fonte: Brasil (2018a), Instituto Brasileiro de Geografia e Estatística (2018).

Inicialmente, reflete-se sobre o grupo 01-Pessoal e Encargos Sociais. Em termos reais, os gastos nesse grupo cresceram de $R \$ 170,1$ bilhões em 2000 para $\mathrm{R} \$ 304,1$ bilhões em 2017 , variação de $3,48 \%$ a.a. A Previdência Social foi a função que 
mais participou com gastos nesse grupo, com $\mathrm{R} \$ 104,5$ bilhões em 2017 e ritmo de 1,62\% a.a. em relação a 2000. Em seguida, também foram expressivos os gastos nas funções de Defesa Nacional (R\$ 47,8 bilhões), Educação, Cultura, Ciência/Tecnologia e Desporto/Lazer ( $\mathrm{R} \$ 46,8$ bilhões), Judiciário e Essencial à Justiça ( $\mathrm{R} \$ 31$ bilhões), Administração ( $R \$ 19,4$ bilhões), Encargos Especiais ${ }^{17}$ (R\$ 18,9 bilhões) e Saúde (R\$10 bilhões). Por sua vez, as demais funções somadas registraram gastos de R\$25,3 bilhões em 2017 e ritmo de 3,33\% a.a. em relação a 2000.

Quanto às funções de Agricultura e Organização Agrária, seus gastos no grupo de Pessoal e Encargos Sociais passaram de R\$2,99 bilhões em 2000 para R\$ 6,12 bilhões em 2017, variação de 4,29\% a.a., acima dos 3,48\% a.a. encontrados para o total nesse grupo de despesa. Mas, ao omitir a função de Previdência Social (principal contribuinte), a variação total no grupo alcançou 4,76\% a.a., superior ao ritmo encontrado nas funções de Agricultura e Organização Agrária. Além disso, destaca-se que o ritmo nessas funções (4,29\% a.a.) ficou aquém das funções de Indústria e Comércio/Serviços (10,16\% a.a.), Comunicações (7,52\% a.a.), Educação, Cultura, Ciência/Tecnologia e Desporto/Lazer (7,10\% a.a.), Urbanismo, Habitação, Saneamento e Transporte (6,36\% a.a.), Defesa Nacional (5,72\% a.a.), Gestão Ambiental (5,85\% a.a.), Encargos Especiais (4,89\% a.a.) e Segurança Pública (4,48\% a.a.).

Com relação ao grupo 03-Outras Despesas Correntes, seus gastos passaram de $\mathrm{R} \$ 446,6$ bilhões para $\mathrm{R} \$ 1,13$ trilhão entre 2000 e 2017, aumento de 5,63\% a.a. A função de Previdência Social foi a que mais participou nesse grupo, com R\$550,9 bilhões em 2017 e ritmo de 6,36\% a.a. em relação a 2000. Também foram expressivos os gastos nas funções de Encargos Especiais ( $R$ \$ 268,1 bilhões), Saúde (R\$92,2 bilhões), Assistência Social e Direitos da Cidadania ( $\$$ \$ 84,6 bilhões), Trabalho (R\$54,1 bilhões) e Educação, Cultura, Ciência/Tecnologia e Desporto/Lazer ( $R$ \$ 40,7 bilhões). As demais funções somaram gastos de $\mathrm{R} \$ 42,2$ bilhões em 2017 e ritmo de crescimento de apenas 0,73\% a.a. em relação a 2000 .

Quanto às funções de Agricultura e Organização Agrária, seus gastos em Outras Despesas Correntes passaram de R\$ 4,84 bilhões em 2000 para R\$ 6,76 bilhões em 2017 (1,99\% a.a.), ritmo aquém do total no grupo de despesa (5,63\% a.a.). Destaca-se ainda que tal variação ficou abaixo do encontrado nas funções de Assistência Social e Direitos da Cidadania (11,61\% a.a.), Trabalho (7,16\% a.a.), Previdência Social (6,36\% a.a.), Judiciário e Essencial à Justiça (5,88\% a.a.), Educação, Cultura, Ciência/Tecnologia e Desporto/Lazer (5,83\% a.a.), Encargos Especiais (4,70\% a.a.), Saúde (3,92\% a.a.), Segurança Pública (3,04\% a.a.), Relações Exteriores (2,18\% a.a.), Legislativo (2,03\% a.a.) e Energia (2,00\% a.a.).

Por sua vez, no grupo 04-Investimentos, os gastos liquidados passaram de $\mathrm{R} \$ 29,49$ bilhões em 2000 para $\mathrm{R} \$ 18,87$ bilhões em 2017, ritmo equivalente a -2,59\% a.a. ${ }^{18}$ Em 2017, a função de Urbanismo, Habitação, Saneamento e Transporte foi a que mais participou com gastos nesse grupo, com $\mathrm{R} \$ 6,92$ bilhões, mas caindo a 1,50\% a.a. em relação a 2000. Em seguida, também contribuíram as funções de Defesa Nacional ( $R \$ 6,06$ bilhões), Educação, Cultura, Ciência/Tecnologia e Desporto/Lazer (R\$1,80 bilhão), Gestão Ambiental ( $R$ \$ 1,03 bilhão), Saúde ( $R$ \$ 0,95 bilhão), Judiciário e Essencial à Justiça ( $R$ \$ 0,70 bilhão) e Assistência Social e Direitos da Cidadania ( $R \$ 0,52$ bilhão). As demais funções somadas registraram gastos de apenas $\mathrm{R} \$ 0,87$ bilhão em 2017 e ritmo de $-10,16 \%$ a.a. em relação a 2000.

Quanto às funções de Agricultura e Organização Agrária, seus gastos no grupo de Investimentos passaram de $\mathrm{R} \$ 1,81$ bilhão para $\mathrm{R} \$ 0,19$ bilhão, entre 2000 e 2017, variação de $12,48 \%$ a.a., mais acentuada que o ritmo de $-2,59 \%$ a.a. de todos os gastos desse grupo. O comportamento na Agricultura e Organização Agrária (-12,48\% a.a.) mostrou-se inferior à dinâmica nas funções de Defesa Nacional (1,08\% a.a.), Justiça e Essencial à Justiça (-0,12\% a.a.), Assistência Social e Direitos da Cidadania (-0,98\% a.a.), Urbanismo, Habitação, Saneamento e

\footnotetext{
${ }^{17}$ No grupo de despesas 01-Pessoal e Encargos Sociais, a função 28-Encargos Especiais compreende basicamente dívidas, ressarcimentos, indenizações e outros gastos afins.

${ }^{18}$ Orair (2014) observa que os investimentos no país são baixos para padrões internacionais. Não bastasse isso, o autor reforça que há grandes riscos de que o investimento público encontre obstáculos para sua expansão, como a falta de fontes adequadas de recursos e o uso de alternativas onerosas e que acumulam passivos de curto prazo.
} 
Transporte (-1,50\% a.a.), Administração (-2,09\% a.a.), Relações Exteriores (-2,09\% a.a.), Educação, Cultura, Ciência/Tecnologia e Desporto/Lazer (-2,82\% a.a.), Gestão Ambiental (-4,07\% a.a.), Legislativo (-4,93\% a.a.), Saúde (-7,75\% a.a.), Trabalho (-8,66\% a.a.), Encargos Especiais ($10,74 \%$ a.a.) e Previdência Social (-11,26\% a.a.).

Com respeito ao grupo 05-Inversões Financeiras, seus gastos liquidados passaram de R\$ 33,4 bilhões para R\$ 63,6 bilhões entre 2000 e 2017 (ritmo de 3,87\% a.a.). A função de Educação, Cultura, Ciência/Tecnologia e Desporto/Lazer foi a que mais participou nesse grupo, com R\$20,5 bilhões em 2017 (12,35\% a.a. em relação a 2000). Também contaram as funções de Encargos Especiais ( $\$$ \$ 18,6 bilhões), Trabalho ( $\$$ 15,7 bilhões ${ }^{19}$ ), Agricultura/Organização Agrária (R\$ 4,2 bilhões), Urbanização, Habitação, Saneamento e Transporte ( $\mathrm{R} \$ 2,30$ bilhões) e Indústria e Comércio/Serviços ( $\mathrm{R} \$ 1,2$ bilhão). Por sua vez, as demais funções somaram R\$1,1 bilhão em 2017 (-3,65\% a.a. em relação a 2000).

Quanto às funções de Agricultura e Organização Agrária, os gastos em Inversões Financeiras passaram de $R \$ 8,40$ bilhões para $R \$ 4,25$ bilhões entre 2000 e 2017 (-3,93\% a.a.), contrastando com o ritmo nos gastos totais desse grupo $(3,87 \%$ a.a.). Nessas funções, a variação só se mostrou maior que a função de Administração (-13,46\% a.a.). Ainda, destacase que, ao somar os gastos nos grupos 04-Investimentos e 05-Inversões Financeiras, as funções de Agricultura e Organização Agrária somaram R\$ 4,4 bilhões liquidados em 2017, menos da metade dos $\mathrm{R} \$ 10,2$ bilhões registrados em 2000 . A queda real de $4,79 \%$ a.a. ficou abaixo do ritmo de todas as funções nesses dois grupos (aumento de 1,61\% a.a. ${ }^{20}$ ). Assim, mesmo tomando a soma dos gastos em Investimentos e Inversões Financeiras, as funções de Agricultura e Organização Agrária tiveram variação menor que a dinâmica geral dos gastos das demais funções.

Por fim, cabe tratar dos grupos de Amortização, Juros e Encargos da Dívida, cujos gastos são registrados apenas na função de Encargos Especiais. Entre 2000 e 2017, em termos reais, os gastos liquidados nesses dois grupos variaram em -0,75\% a.a., passando de $\mathrm{R} \$ 1,12$ trilhão para $\mathrm{R} \$ 986,1$ bilhões entre 2000 e 2017. O grupo de Amortização passou de $R \$ 1,01$ trilhão em 2000 para $R \$ 783$ bilhões em 2017, queda da ordem de $-1,47 \%$ a.a. Por sua vez, o grupo de Juros e Encargos evoluiu de $\mathrm{R} \$ 113,4$ bilhões em 2000 para $\mathrm{R} \$ 203,1$ bilhões em 2017, crescendo 3,49\% a.a. Conforme descrito na seção Metodologia, ressalta-se que, apesar da elevada participação desses dois grupos no orçamento da União, tais recursos são particularmente cobertos por operações financeiras de rolagem da dívida.

\section{ORÇAMENTO VOLTADO AO MEIO RURAL}

Esta seção traz o comportamento dos recursos especificamente destinados ao meio rural. Inicialmente, os gastos nas funções 20-Agricultura e 21-Organização Agrária são detalhados segundo grupos de despesa e órgãos orçamentários. Em seguida, contemplam-se as mesmas funções, mas discriminadas por ações específicas. Por fim, agregam-se os gastos voltados ao meio rural, mas não registrados nas funções 20-Agricultura e 21-Organização Agrária.

Particularmente aos gastos das funções 20-Agricultura e 21-Organização Agrária, salienta-se que sua distribuição nos grupos de despesa é relativamente homogênea, exceto pelo reduzido montante destinado ao grupo 04-Investimentos ( $R \$ 0,19$ bilhão em 2017 e ritmo de $-12,48 \%$ a.a. em relação a 2000). Quanto aos demais grupos, em 2017, registraram-se $\mathrm{R} \$ 6,8$ bilhões em 03-Outras Despesas Correntes (1,99\% a.a.), R\$ 6,1 bilhões em 01-Pessoal e Encargos Sociais (4,29\% a.a.) e $\mathrm{R} \$ 4,2$ bilhões em 05-Inversões Financeiras (-3,93\% a.a.). Como descrito anteriormente, os grupos 02-juros e Encargos da Dívida e 06-Amortização da Dívida não contaram com gastos associados a outras funções que não o código 28-Encargos Especiais.

Conforme ilustrado na Figura 5, o comportamento de queda nas funções de Agricultura e Organização Agrária se acentuou, principalmente, a partir de 2007. Além disso, percebe-se

\footnotetext{
${ }^{19}$ Nessa função, entre 2000 e 2012, não houve dotação para o grupo de Inversões Financeiras.

${ }^{20}$ No orçamento geral, a soma dos grupos Investimentos e Inversões Financeiras registraram R\$62,8 bilhões em 2000 e R \$ 82,4 bilhões em 2017, com foco em Educação, Cultura, Ciência/Tecnologia e Desporto/Lazer (R $\$ 22,3$ bilhões em 2017 e ritmo de 8,28\% a.a. em relação a 2000), Encargos Especiais ( $\$$ \$ 18,6 bilhões e ritmo de 0,39\% a.a.), Trabalho (R\$ 15,7 bilhões e 31,7\% a.a.), Urbanismo, Habitação, Saneamento e Transporte (R\$ 9,2 bilhões e -0,27\% a.a.) e Defesa Nacional (R\$ 6,5 bilhões e 1,51\% a.a.).
} 
que o grupo 01-Pessoal e Encargos Sociais apresentou evolução, enquanto o grupo 03-Outras Despesas Correntes demonstrou volatilidade, com picos nos anos de 2006, 2015 e 2016. Além disso, são marcantes as reduções reais observadas nos grupos 04-Investimentos e 05Inversões Financeiras ao longo de todo o horizonte estudado.

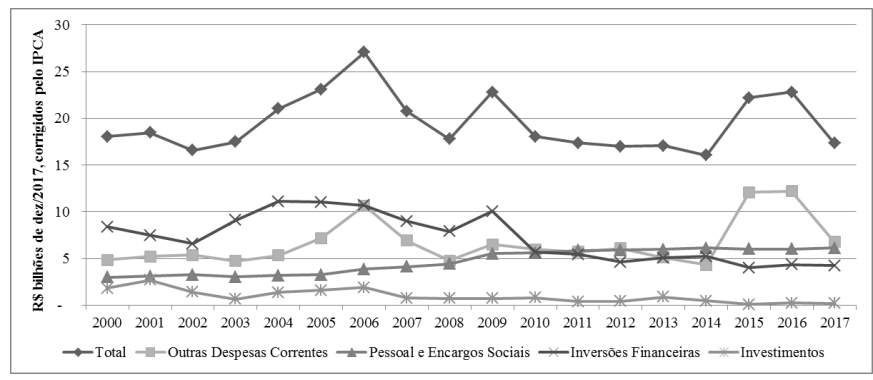

Figura 5. Gastos liquidados nas funções de Agricultura e Organização Agrária, segundo grupos de despesa. Fonte: Brasil (2018a), Instituto Brasileiro de Geografia e Estatística (2018).

\subsection{Gastos por grupos de despesa e unidades orçamentárias}

Esta subseção detalha cada grupo de despesa segundo unidades orçamentárias, tratando-se especificamente das funções de Agricultura e Organização Agrária. De início, quanto ao grupo Outras Despesas Correntes, tem-se que o Ministério da Fazenda foi o principal responsável, com $\mathrm{R} \$ 4,39$ bilhões em 2017 e ritmo de 3,71\% a.a. em relação a 2000. Esses gastos se associam a subvenções econômicas em operações de crédito para o meio rural (Figura 6), sobretudo no Programa Nacional de Fortalecimento da Agricultura Familiar (PRONAF), cujos recursos somaram $\mathrm{R} \$ 2,06$ bilhões em 2017 e variação de 3,14\% a.a. em relação a $2000^{21}$.

Quanto a outras unidades (Figura 7), destacaram-se o Ministério da Agricultura, com $\mathrm{R} \$ 894,1$ milhões em 2017 e ritmo de $-0,73 \%$ a.a. em relação a 2000, e a Secretaria Especial da Agricultura Familiar e do Desenvolvimento Agrário, com R $\$ 582,1$ milhões e 6,25\% a.a. Em menor grau, ainda participaram a Empresa Brasileira de Pesquisa Agropecuária (EMBRAPA), com $\mathrm{R} \$ 333,1$ milhões em 2017 e variação de -0,48\% a.a. em relação a 2000, o Instituto Nacional de Colonização e Reforma Agrária (INCRA), com R\$315,8 milhões e -3,33\% a.a., a Companhia Nacional de Abastecimento (CONAB), com R\$200,8 milhões e 0,46\% a.a., a Companhia de Desenvolvimento dos Vales do São Francisco e do Parnaíba (CODEVASF), com $\mathrm{R} \$ 43,1$ milhões e $-4,34 \%$ a.a., e o Ministério da Integração ${ }^{22}$, com $\mathrm{R} \$ 5,1$ milhões em 2017 e variação de $-12,95 \%$ a.a. em relação ao registrado em 2000.

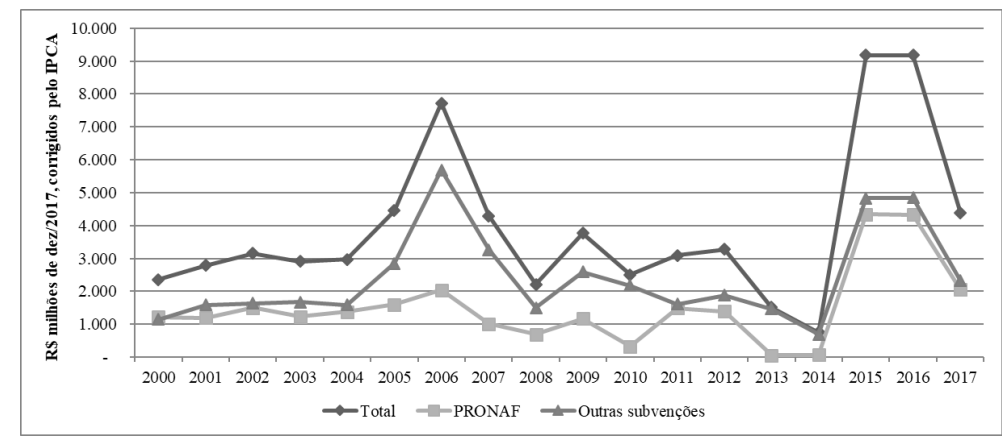

Figura 6. Gastos liquidados em Outras Despesas Correntes, nas funções de Agricultura e Organização Agrária, relativos a subvenções sob responsabilidade do Ministério da Fazenda. Fonte: Brasil (2018a), Instituto Brasileiro de Geografia e Estatística (2018).

\footnotetext{
${ }^{21}$ Esse volume não coincide com os créditos concedidos pelo PRONAF no país, já que estes contam com fontes que transbordam o orçamento geral da União, a exemplo de poupança rural.

${ }^{22}$ Incluindo a Superintendência do Desenvolvimento do Nordeste (SUDENE), a Superintendência do Desenvolvimento da Amazônia (SUDAM) e o Departamento Nacional de Obras Contra as Secas (DNOCS).
} 


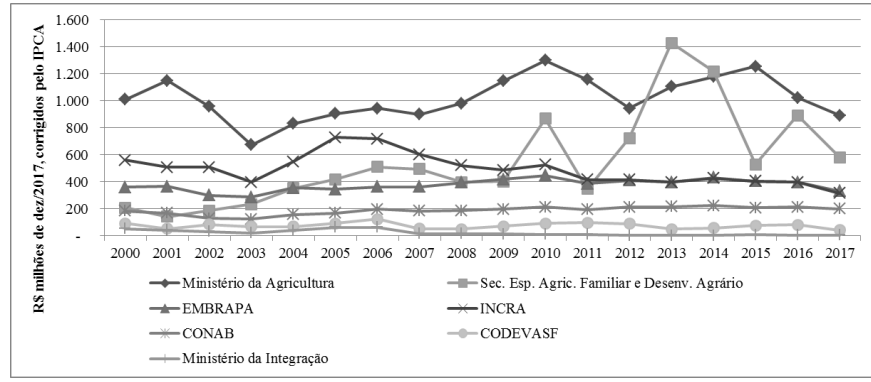

Figura 7. Gastos liquidados em Outras Despesas Correntes, nas funções de Agricultura e Organização Agrária, segundo unidades orçamentárias (exceto Ministério da Fazenda). Fonte: Brasil (2018a), Instituto Brasileiro de Geografia e Estatística (2018).

Com relação aos gastos no grupo de Pessoal e Encargos Sociais (Figura 8), a principal unidade orçamentária na função de Agricultura e Organização Agrária foi a EMBRAPA, com $\mathrm{R} \$ 2,84$ bilhões em 2017 e crescimento de $5,15 \%$ a.a. em relação a 2000. Quanto às demais unidades no grupo, destacaram-se o Ministério da Agricultura ( $R \$ 1,74$ bilhão em 2017 e

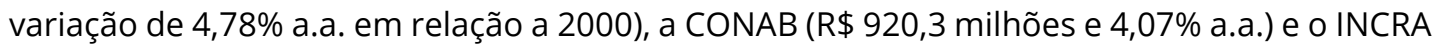
( $\mathrm{R} \$ 570,7$ milhões e 0,46\% a.a.). Em menor grau, participou ainda a Secretaria Especial da Agricultura Familiar e do Desenvolvimento Agrário (R\$ 49,4 milhões em 2017 e evolução de $14,89 \%$ a.a. em relação a 2000).

Por sua vez, quanto ao grupo de Inversões Financeiras (Figura 9), em 2017, destacou-se 0 Ministério da Agricultura, com R\$3,25 bilhões e variação de 3,01\% a.a. em relação a 2000. Tal volume está integralmente associado ao Fundo de Defesa da Economia Cafeeira, que financia o agronegócio do café. Quanto a outras unidades, destacaram-se a CONAB, com R $\$ 678,7$ milhões em 2017 e $-5,89 \%$ a.a. em relação a 2000, o INCRA, com R\$ 265,5 milhões e $-10,51 \%$ a.a., e, em menor grau, o Ministério da Fazenda, com $\mathrm{R} \$ 53,8$ milhões e $-20,71 \%$ a.a., e a Secretaria Especial da Agricultura Familiar e do Desenvolvimento Agrário, com R\$1,7 milhão em 2017 e ritmo de $33,21 \%$ a.a. em relação a 2006, já que antes disso não havia registros nessa unidade.

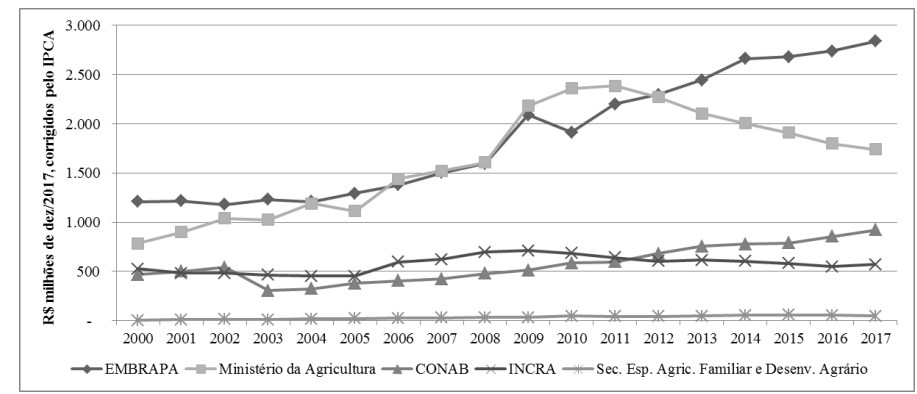

Figura 8. Gastos liquidados em Pessoal e Encargos Sociais, nas funções de Agricultura e Organização Agrária, segundo unidades orçamentárias. Fonte: Brasil (2018a), Instituto Brasileiro de Geografia e Estatística (2018).

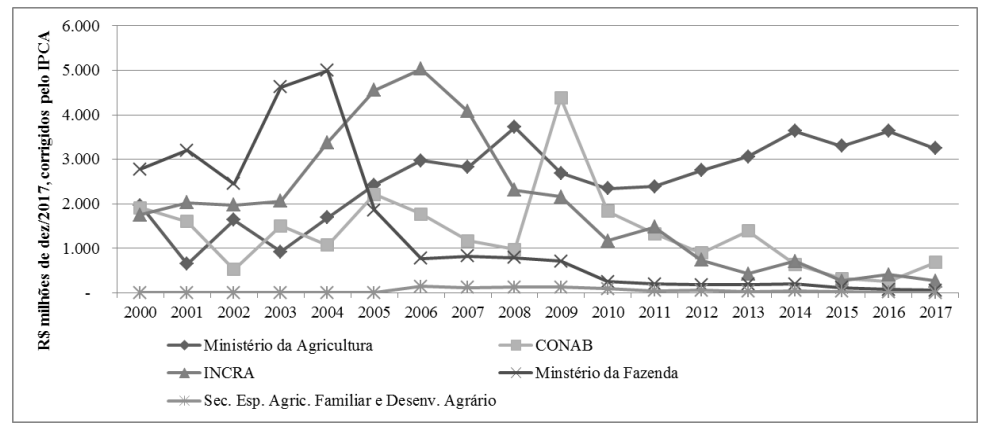

Figura 9. Gastos liquidados em Inversões Financeiras, nas funções de Agricultura e Organização Agrária, segundo unidades orçamentárias. Fonte: Brasil (2018a), Instituto Brasileiro de Geografia e Estatística (2018). 
É importante observar três movimentos interessantes na Figura 9: i) a substancial queda referente ao Ministério da Fazenda, o qual, principalmente até 2004, apresentava gastos consideráveis relacionados à subvenção em operações do PRONAF e à política de aquisições para formação de estoques reguladores; ii) os picos associados ao INCRA, entre 2004 e 2007, associados à política de obtenção de imóveis rurais para a reforma agrária; e iii) o salto de gastos da CONAB, em 2009, relativo à formação de estoques reguladores. Percebe-se que parte das alterações observadas nesse grupo está associada a mudanças na metodologia de classificação dos gastos, sobretudo por manejo entre diferentes unidades orçamentárias.

Por fim, no grupo de Investimentos (Figura 10), o principal contribuinte nas funções de Agricultura e Organização Agrária, em 2017, foi o Ministério da Agricultura, com $\mathrm{R} \$ 117,8$ milhões (-7,80\% a.a. em relação a 2000$)$, sobretudo quanto ao fomento à agricultura sustentável. Outros participantes foram o INCRA, com R\$34,9 milhões e $-12,14 \%$ a.a., a Secretaria Especial da Agricultura Familiar e do Desenvolvimento Agrário, com $\mathrm{R} \$ 17,3$ milhões e $-16,85 \%$ a.a., a CODEVASF, com $\mathrm{R} \$ 13,3$ milhões e $-15,15 \%$ a.a., e, em menor grau, o Ministério da Integração ${ }^{23}$, com $\mathrm{R} \$ 2,1$ milhões e $-26,05 \%$ a.a., a EMBRAPA, com $\mathrm{R} \$ 1,2$ milhão e $-19,23 \%$ a.a., e a CONAB, com $\mathrm{R} \$ 1,1$ milhão e $-11,26 \%$ a.a. O pico nos gastos da Secretaria da Agricultura Familiar e do Desenvolvimento Agrário, em 2013, associou-se ao apoio ao desenvolvimento sustentável em áreas rurais e à aquisição de máquinas e equipamentos para recuperação de estradas vicinais.

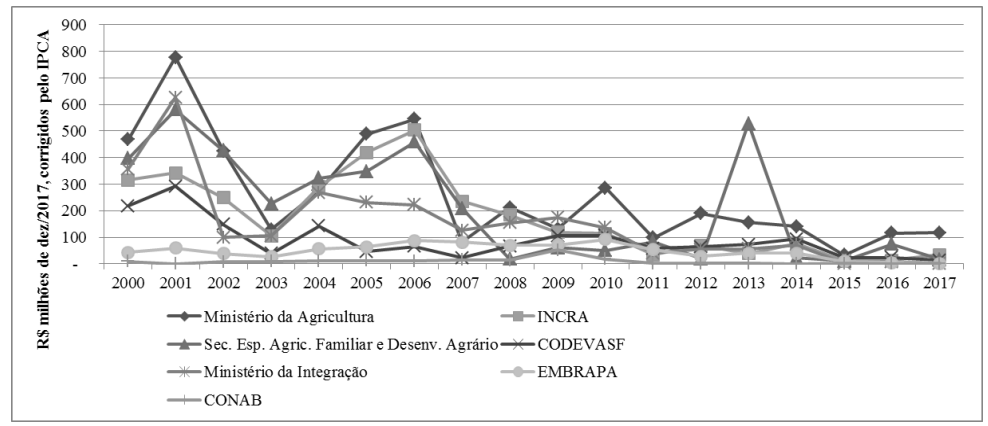

Figura 10. Gastos liquidados em Investimentos, nas funções de Agricultura e Organização Agrária, segundo unidades orçamentárias. Fonte: Brasil (2018a), Instituto Brasileiro de Geografia e Estatística (2018).

\subsection{Gastos com programas e ações específicas}

Como visto nas seções anteriores, algumas importantes políticas nas funções de Agricultura e Organização Agrária têm seus gastos distribuídos entre várias unidades orçamentárias. Assim, é oportuno analisar a evolução dos gastos em ações específicas. Porém, como não é possível detalhar os gastos com Pessoal e Encargos Sociais segundo tais políticas, esta subseção apenas recai sobre a evolução dos gastos nos grupos de Outras Despesas Correntes, Investimentos e Inversões Financeiras, nas funções de Agricultura e Organização Agrária.

A Figura 11 traz os gastos em ações de assistência técnica e extensão rural, pesquisa, desenvolvimento e inovação, e defesa agropecuária. Em 2017, ações de assistência técnica e extensão rural somaram $\mathrm{R} \$ 199,4$ milhões (-1,94\% a.a. em relação a 2000), enquanto ações de pesquisa, desenvolvimento e inovação chegaram a $R \$ 176,1$ milhões $(-6,26 \%$ a.a.) e ações com defesa agropecuária consumiram $\mathrm{R} \$ 125,6$ milhões (-4,40\% a.a.).

$\mathrm{Na}$ Figura 12, tem-se a evolução dos gastos em ações para agricultura familiar, assentamentos, comunidades tradicionais (quilombolas, indígenas etc.) e reforma agrária. Nessa análise, detalham-se gastos com PRONAF ${ }^{24}$ (R\$ 2,11 bilhões em 2017 e ritmo de

${ }^{23}$ Incluindo SUDENE, SUDAM e DNOCS.

${ }^{24}$ Sobretudo subvenções econômicas, mas também remunerações a operadores financeiros e incentivos a estudos relacionados ao programa. Tal resultado se refere a todos os gastos relativos ao PRONAF provenientes do orçamento geral da União, tanto no grupo de Outras Despesas Correntes (sobretudo) quanto no grupo de Inversões Financeiras. Além disso, ressalta-se que não há referências ao PRONAF no grupo de Investimentos. Ademais, como antes colocado, esse volume não coincide com os créditos concedidos pelo PRONAF no país, já que o programa conta com outras fontes, além do orçamento geral da União, a exemplo de poupança rural. 
0,42\% a.a. em relação a 2000), incentivos à Reforma Agrária ${ }^{25}$ ( $R \$ 122,6$ milhões e $-12,83 \%$ a.a.) e outras formas de $\operatorname{apoio}^{26}$ ( $R \$ 258$ milhões e $-5,97 \%$ a.a.).

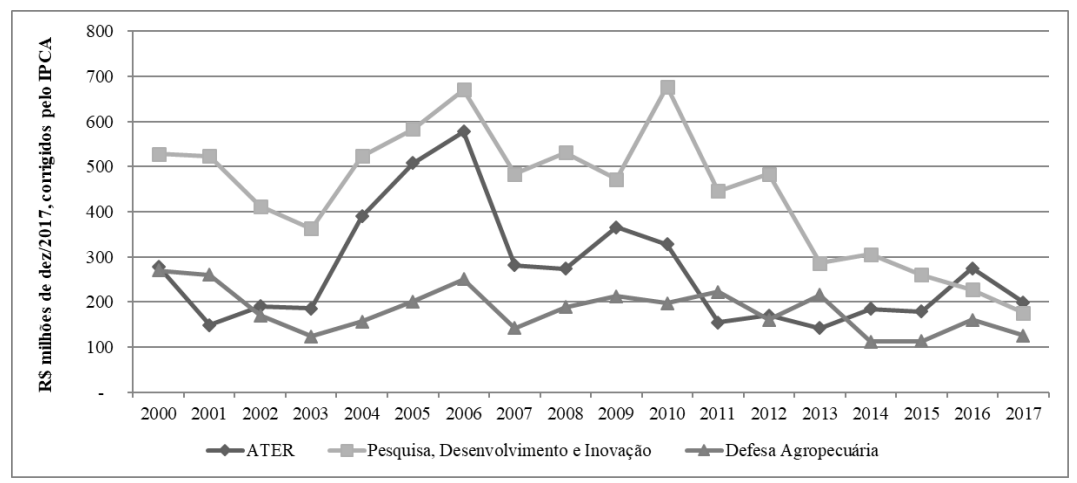

Figura 11. Gastos liquidados em ações de assistência técnica e extensão rural, pesquisa, desenvolvimento e inovação, e defesa agropecuária. Fonte: Brasil (2018a), Instituto Brasileiro de Geografia e Estatística (2018)

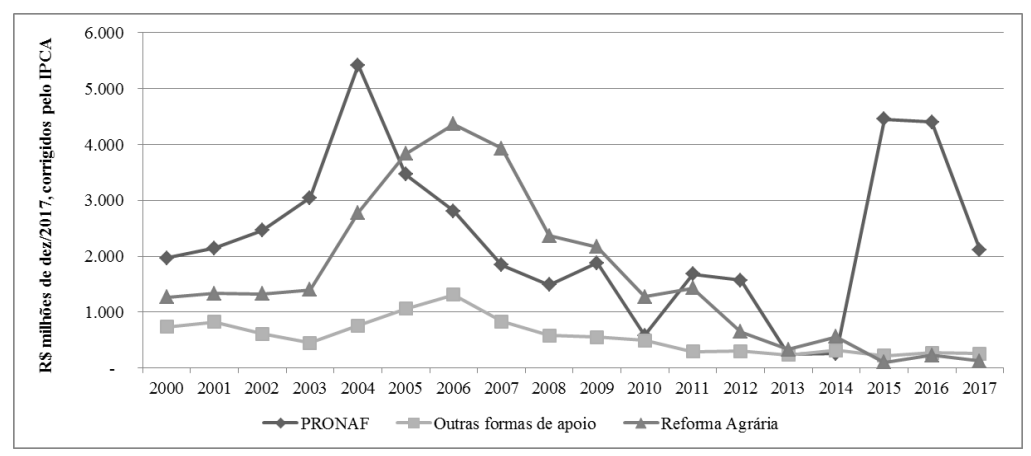

Figura 12. Gastos liquidados em ações voltadas à agricultura familiar, aos assentamentos, às comunidades tradicionais (quilombolas, indígenas etc.) e à reforma agrária. Fonte: Brasil (2018a), Instituto Brasileiro de Geografia e Estatística (2018).

Outro importante estrato de ações refere-se às políticas de crédito, tratadas na Figura 13. Nesse contexto, destaca-se o consistente crescimento do financiamento destinado ao agronegócio do café, cujos gastos somaram $\mathrm{R} \$ 3,34$ bilhões somente em 2017, com crescimento de $7,70 \%$ a.a. em relação a 2000. Como comentado anteriormente, outro relevante volume de gastos concerne ao PRONAF (R\$ 2,11 bilhões em 2017 e ritmo de $0,42 \%$ a.a. em relação a 2000). Por sua vez, quanto a outras formas de crédito ${ }^{27}$, os gastos compreenderam $\mathrm{R} \$ 2,34$ bilhões em 2017, com ritmo de 1,46\% a.a. em relação a 2000.

Por sua vez, a Figura 14 volta-se à política de sustentação de preços e à política de garantias e seguros rurais. Quanto à formação de estoques ${ }^{28}$, seus gastos chegaram a $\mathrm{R} \$ 891,3$ milhões em 2017, com ritmo de $-10,12 \%$ a.a. em relação a 2000 e evolução fortemente volátil ao longo do período estudado. Com respeito à política de garantias e seguros rurais ${ }^{29}$, os gastos em 2017 somaram $R \$ 740,3$ milhões, com evolução de $28,24 \%$ a.a. em relação a 2000.

\footnotetext{
${ }^{25}$ Principalmente para obtenção de imóveis rurais, mas também ações como identificação, mediação e crédito para instalação de assentamentos. Nesse aspecto, vale notar que a forte redução desses gastos está relacionada com a exaustão do processo de reforma agrária, tratada por Guedes e Fleury (2016), somada a problemas como abandono de lotes, irregularidades na distribuição da terra e esvaziamento demográfico no meio rural.

${ }^{26}$ Incluindo melhorias de infraestruturas, apoio à comercialização, assistência técnica e extensão rural, pesquisa, desenvolvimento e inovação, entre outras formas de apoio direcionadas a esses tipos de beneficiários.

${ }^{27} \mathrm{Em}$ operações de aquisição de imóveis rurais, realização de investimentos, custeio agropecuário e alongamento de dívidas.

${ }^{28}$ Sobretudo associada a Aquisições do Governo Federal (AGF).

${ }^{29}$ Principalmente subvenções ao Prêmio do Seguro Rural e contribuições ao Fundo Garantia-Safra.
} 


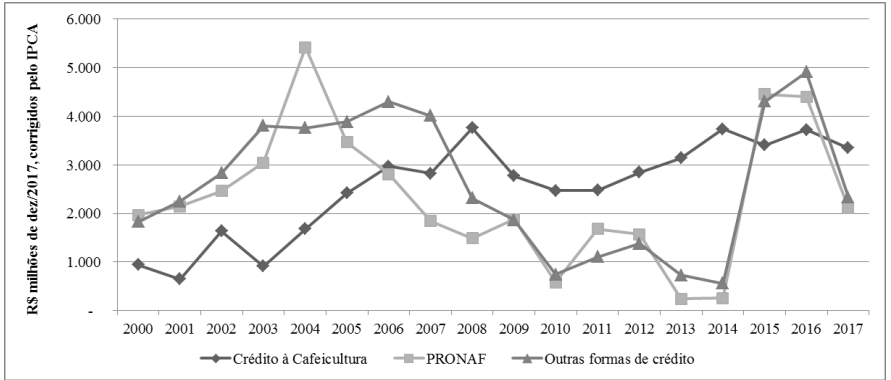

Figura 13. Gastos liquidados em ações voltadas à concessão de créditos. Fonte: Brasil (2018a), Instituto Brasileiro de Geografia e Estatística (2018).

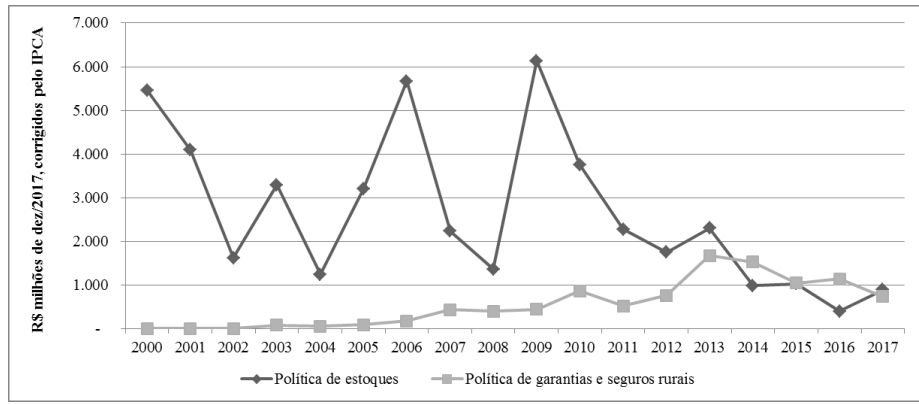

Figura 14. Gastos liquidados em ações voltadas às políticas de sustentação de preços e às políticas de garantias e seguros rurais. Fonte: Brasil (2018a), Instituto Brasileiro de Geografia e Estatística (2018).

Na Figura 15, há evolução de gastos voltados a apoios diversos que não foram descritos anteriormente. Inicialmente, destacam-se os gastos em infraestrutura de projetos de irrigação ${ }^{30}$, cujos valores somaram apenas $\mathrm{R} \$ 53,7$ milhões em 2017, com queda equivalente a $-13,66 \%$ a.a. em relação a 2000 . Quanto aos gastos relacionados a outras infraestruturas ${ }^{31}$, foram registrados somente $R \$ 3,3$ milhões em 2017 e ritmo de $-21,14 \%$ a.a. em relação a 2000. Por sua vez, no que diz respeito às demais ações não citadas anteriormente ${ }^{32}$, os recursos somaram $R \$ 164,1$ milhões em 2017, variando -10,56\% a.a. em relação a 2000.

Por fim, a Figura 16 ilustra dois estratos específicos, analisados em separado por apresentarem comportamento crescente ao longo do período estudado, bem como um considerável volume de gastos. O primeiro diz respeito aos gastos com gestão ${ }^{33}$, cujos recursos somaram R\$ 882,6 milhões em 2017, com ritmo de 3,60\% a.a. em relação a 2000. Por sua vez, outra ação específica, identificada como desenvolvimento da maricultura, registrou R\$ 446,5 milhões em 2017, com variação de 5,77\% a.a. em relação a 2000.

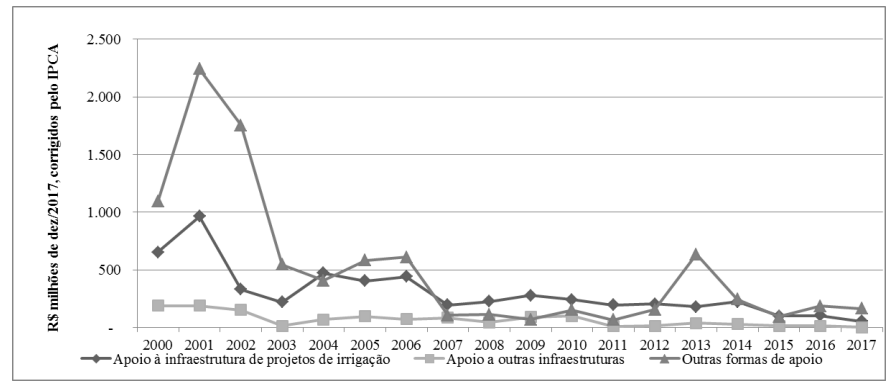

Figura 15. Gastos liquidados em ações voltadas à infraestrutura e outros apoios não citados anteriormente. Fonte: Brasil (2018a), Instituto Brasileiro de Geografia e Estatística (2018).

\footnotetext{
${ }^{30} \mathrm{Com}$ ênfase em implantações e transferências de gestão de perímetros irrigados.

${ }^{31}$ Basicamente associadas a reformas de estruturas prediais dos órgãos federais.

${ }^{32}$ Essencialmente projetos voltados a prefeituras e fomento geral ao setor agropecuário.

${ }^{33}$ Sobretudo gastos administrativos dos órgãos federais e assistências/auxílios a servidores desses órgãos.
} 


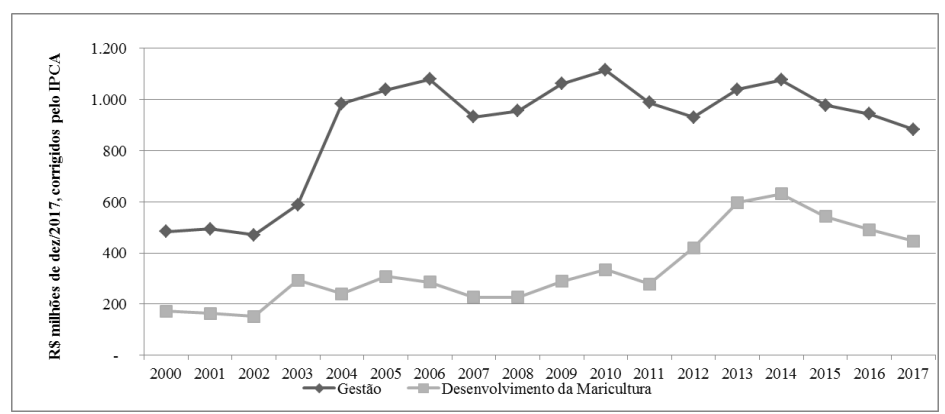

Figura 16. Gastos liquidados em ações específicas: gestão dos órgãos federais e desenvolvimento da maricultura. Fonte: Brasil (2018a), Instituto Brasileiro de Geografia e Estatística (2018).

\subsection{Agregando outros gastos relacionados ao meio rural e consolidando os resultados}

Além dos gastos nas funções de Agricultura e Organização Agrária, ressaltam-se ainda outros importantes elementos associados ao meio rural, mas classificados em outras funções. Para tanto, buscou-se levantar ações cujas descrições contivessem termos relacionados, conforme exposto na seção Metodologia. Nesse contexto, o principal elemento referiu-se à função de Previdência Social, mas relativo particularmente a gastos com beneficiários rurais. Esse valor chegou a $R \$ 117,4$ bilhões em 2017, com crescimento real de 7,55\% a.a. em relação a 2000. Em seguida, mas com gastos relativamente menores, encontrou-se a função de Encargos Especiais, com R $\$ 9,86$ bilhões em 2000, passando para $\mathrm{R} \$ 1,88$ bilhão em 2017 (-9,28\% a.a.) $)^{34}$. Nessa função, destacaram-se ações como transferência do Imposto Territorial Rural aos municípios ${ }^{35}$ e gastos associados ao Programa de Garantia da Atividade Rural (PROAGRO) ${ }^{36}$.

Além desses elementos, salienta-se ainda as ações de aquisição de alimentos provenientes da agricultura familiar, por meio do Programa de Aquisição de Alimentos (PAA), contabilizado na função de Assistência Social. Os gastos do PAA passaram de $R \$ 494,3$ milhões em 2003, ano em que foi criado, para R $\$ 136,1$ milhões em 2017 (queda real de $-8,80 \%$ a.a.). Ademais, quando somados os gastos em outras ações associadas ao meio rural (exceto aquelas descritas nas funções de Agricultura e Organização Agrária, bem como as ações na função de Previdência Social, na de Encargos Especiais e no PAA), observa-se que estes passaram de $\mathrm{R} \$ 235,5$ milhões em 2000 para $\mathrm{R} \$ 383,7$ milhões em 2017 (2,91\% a.a.) ${ }^{37}$.

Diante do exposto, os principais gastos do orçamento federal, particularmente voltados ao meio rural, referem-se à Previdência Social, com $R \$ 117,4$ bilhões destinados a beneficiários rurais em 2017 e crescimento de 7,55\% a.a. em relação a 2000. Quanto às funções de Agricultura e Organização Agrária, como já descrito, os gastos chegaram a R\$17,3 bilhões em 2017, com variação equivalente a $-0,24 \%$ a.a. em relação a 2000 . Por fim, quanto aos gastos classificados em outras funções, mas também identificados com o meio rural, foram computados $R \$ 2,4$ bilhões em 2017, com variação real de $-8,09 \%$ a.a. em relação a 2000.

Ao se agregar tais valores, calcula-se que os gastos do orçamento federal voltados ao meio rural alcançaram $R \$ 137,07$ bilhões em 2017 , o que representa 5,47\% do orçamento geral, cujos gastos chegaram a $R \$ 2,51$ trilhões no mesmo ano. Mesmo considerando somente os grupos 01 Pessoal e Encargos Sociais, 03-Outras Despesas Correntes, 04-Investimentos e 05-Inversões Financeiras, o que resultou em gastos de $R \$ 1,52$ trilhão no orçamento geral de $2017^{38}$, a participação dos $\mathrm{R} \$ 137,07$ bilhões alocados ao meio rural alcançou apenas 9,02\%.

Ao se descartar os gastos com a função de Previdência Social, tem-se que os gastos direcionados ao meio rural somaram $\mathrm{R} \$ 19,7$ bilhões em $2017^{39}$ (ritmo de $-2,07 \%$ a.a. em relação a 2000). Para efeito de comparação, ao também se descartar a Previdência Social do orçamento geral

\footnotetext{
${ }^{34}$ Sobretudo decorrente da redução da prática de rolagem da dívida associada ao fomento a créditos rurais. ${ }^{35}$ Com R $\$ 298,6$ milhões em 2000 e R\$ 931 milhões em 2017 (crescimento de 6,92\% a.a.).

${ }^{36}$ Com $R \$ 306,5$ milhões em 2000 e $R \$$ 659,5 milhões em 2017 (crescimento de 4,61\% a.a.).

${ }^{37}$ Nesse caso, a evolução demonstrou comportamento volátil, com destaque para gastos na função de Administração, particularmente associados à execução dos Censos Agropecuários.

${ }^{38} \mathrm{Ou}$ seja, esse valor exclui os gastos nos grupos 02-Juros e Encargos da Dívida e 06-Amortização da Dívida.

${ }^{39}$ Assim, esse valor apenas considera as funções 20-Agricultura e 21-Organização Agrária, além de outros gastos relacionados com o meio rural, mas identificados em outras funções, exceto 09-Previdência Social.
} 
de $R \$ 1,52$ trilhão em 2017, chegou-se a um resultado de $R \$ 864$ bilhões ${ }^{40}$ (4,53\% a.a. em relação a 2000). Assim, desconsiderando a função de Previdência Social, os $R \$ 19,7$ bilhões voltados ao meio rural participaram com apenas 2,28\% do orçamento geral de R\$ 864 milhões em 2017 (em 2000, esse percentual era de 6,92\%, parcela já bastante tímida).

Pode-se argumentar que há outros gastos que beneficiam a população rural, mas que não são particularmente descritos por termos relacionados ao campo, a exemplo de gastos em funções como Educação e Saúde. Assim, ao se considerar a hipótese ampliada de que tais recursos podem apoiar o meio rural na mesma proporção de seus habitantes em relação ao total da população brasileira ${ }^{41}$, pode-se calcular que outros $\mathrm{R} \$ 129$ bilhões do orçamento podem beneficiar o meio rural. A Tabela 2 procura sintetizar tais informações, ressaltando a parcela do orçamento federal que é particularmente direcionada ao meio rural brasileiro.

Salienta-se que este artigo se restringiu a analisar o orçamento geral da União e a parcela de seus gastos voltados particularmente ao ambiente rural. Portanto, não coube aqui descrever incentivos que usam recursos externos ao orçamento, mesmo que sejam relevantes, a exemplo do crédito rural. Porém, a título de ilustração, informa-se que o sistema financeiro nacional concedeu, em 2017, um volume de $R \$ 162,2$ bilhões em crédito rural, crescendo a um expressivo ritmo de 8,55\% a.a. em relação a 2000 (Banco Central do Brasil, 2018). Contudo, ao se calcular a participação do crédito rural no total de concessões de créditos a pessoas jurídicas, em 2017, registrados no sistema financeiro nacional, esse percentual correspondeu a somente $11,31 \%{ }^{42}$.

Tabela 2. Gastos liquidados no orçamento federal em 2017, totais e destinados ao meio rural (valores em $\mathrm{R} \$$ bilhões e taxa de crescimento real equivalente em \% a.a. em relação a 2000).

\begin{tabular}{|c|c|c|c|c|c|}
\hline \multirow{2}{*}{ Discriminação } & \multirow{2}{*}{ R\$ bi } & \multirow{2}{*}{$\%$ a.a. } & \multicolumn{3}{|c|}{ Participação nos gastos (\%) } \\
\hline & & & Em (a) & Em (b) & $\operatorname{Em}(c)$ \\
\hline (a) Gastos totais do orçamento & $2.505,6$ & 1,96 & - & - & - \\
\hline $\begin{array}{l}\text { (b) Gastos do orçamento, excluindo-se os grupos 02-Juros/Encargos da Dívida } \\
\text { e 06-Amortiz. da Dívida }\end{array}$ & $1.519,5$ & 4,85 & 60,64 & - & - \\
\hline $\begin{array}{l}\text { (c) Gastos do orçamento, excluindo-se os grupos 02. Juros/Encargos da Dívida e } \\
\text { 06-Amortiz. da Dívida, além da função 09-Previdência Social }\end{array}$ & 864,0 & 4,53 & 34,48 & 56,86 & - \\
\hline (d) Gastos nas funções 20-Agricultura e 21-Organização Agrária & 17,3 & $-0,24$ & 0,69 & 1,14 & 2,00 \\
\hline $\begin{array}{l}\text { (e) Gastos na função 09-Previdência Social, especificamente direcionados ao } \\
\text { meio rural (i) }\end{array}$ & 117,4 & 7,55 & 4,68 & 7,72 & - \\
\hline (f) Gastos em outras funções, especificamente direcionados ao meio rural & 2,4 & $-8,09$ & 0,10 & 0,16 & 0,28 \\
\hline $\begin{array}{l}\text { (g) Gastos em outras funções, não direcionados especificamente ao meio rural } \\
\text { (hipótese ampliada) }{ }^{(i)}\end{array}$ & 129,0 & 4,51 & 5,15 & 8,49 & 14,93 \\
\hline$(\mathrm{d}+\mathrm{e}+\mathrm{f}+\mathrm{g})$ Gastos totais direcionados ao meio rural (hipótese ampliada) ${ }^{(\mathrm{i})(\mathrm{ii})}$ & 266,0 & 4,59 & 10,62 & 17,51 & - \\
\hline$(\mathrm{d}+\mathrm{e}+\mathrm{f})$ Gastos totais especificamente direcionados ao meio rural ${ }^{(1)}$ & 137,1 & 4,66 & 5,47 & 9,02 & - \\
\hline $\begin{array}{l}(\mathrm{d}+\mathrm{f}) \text { Gastos totais especificamente direcionados ao meio rural, exceto na } \\
\text { função 09-Previdência Social }\end{array}$ & 19,7 & $-2,07$ & 0,79 & 1,30 & 2,28 \\
\hline
\end{tabular}

Notas: (i) Visto que o agregado de gastos (e) é um dos componentes do agregado (c), não faz sentido calcular a participação desses gastos sobre (c), razão pela qual, nesses casos, não foram informados valores para a última coluna da tabela; (ii) O agregado (g) considera gastos que podem beneficiar a população rural, mas não são particularmente identificados, sendo calculados ao adotar a hipótese de que os gastos em outras funções seriam destinados ao meio rural pela proporção de seus habitantes no total da população brasileira. Fonte: Brasil (2018a), Instituto Brasileiro de Geografia e Estatística (2018).

\footnotetext{
${ }^{40}$ Esse valor, portanto, representa o orçamento geral, excluindo-se os gastos nos grupos 02-Juros e Encargos da Dívida e 06-Amortização da Dívida, além dos gastos na função 09-Previdência Social.

${ }^{41} \mathrm{Em}$ 2015, o meio rural abrigava 15,3\% da população brasileira (Instituto Brasileiro de Geografia e Estatística, 2018).

${ }^{42} \mathrm{Em}$ particular, colocam-se as seguintes informações (Brasil, 2018d; Banco Central do Brasil, 2018; Banco Nacional de Desenvolvimento Econômico e Social, 2018): i) só com o PRONAF, as concessões chegaram a R\$ 21 bilhões em 2017 (ritmo de 8,25\% a.a. em relação a 2000); ii) no âmbito do Banco Nacional de Desenvolvimento Social e Econômico (BNDES), as concessões ao setor rural alcançaram R \$ 14,4 bilhões em 2017 (5,73\% a.a. em relação a 2000), chegando a 20,32\% de todos os desembolsos da instituição; e iii) no total dos Fundos Constitucionais de Desenvolvimento (do Norte, FNO; do Centro-Oeste, FCO; e do Nordeste, FNE), os desembolsos para o meio rural chegaram a R \$14,7 bilhões em 2017 (ritmo de 7,84\% a.a. em relação a 2000), representando $54 \%$ de todos os desembolsos realizados por meio desses fundos.
} 
Ademais, pode-se comparar os resultados da Tabela 2 aos dados agregados pela Organização das Nações Unidas para a Alimentação e a Agricultura (Food and Agriculture Organization of the United Nations, 2018a). Para o Brasil, em 2017, a instituição apontou que o gasto do governo central com o setor rural chegou a $\mathrm{R} \$ 19,9$ bilhões, muito próximo à estimativa indicada no agregado $(d+f)$ da Tabela 2. Contudo, salienta-se que os dados são desencontrados quanto ao valor global dos gastos da União, pois a Food and Agriculture Organization of the United Nations (2018a) informa que a participação dos gastos com o setor rural chegou a 0,91\% do orçamento total, em vez de 0,79\%, como calculado neste trabalho. Assim mesmo, entende-se que esse nível é tímido, abaixo de 1\% dos gastos totais do orçamento ${ }^{43}$. Mesmo não indicando um percentual recomendado, a FAO considera a razão entre a contribuição do governo central para o setor rural e a contribuição do setor para o PIB como um indicador do progresso dos países em alcançar o segundo alvo da Agenda 2030 para o Desenvolvimento Sustentável ${ }^{44}$ (Food and Agriculture Organization of the United Nations, 2018b). Para o Brasil, em 2017, esse número chegou a 0,203, abaixo do encontrado para Rússia $(0,420)$, Índia $(0,421)$, China $(0,289)$, África do Sul $(0,596)$, México $(0,512)$, Chile $(0,419)$, Israel $(0,437)$ e França $(0,519)$, por exemplo.

Outra importante ressalva diz respeito à não avaliação, neste trabalho, sobre a qualidade dos gastos públicos. Seguindo Santos e Freitas (2017), vale reconhecer que a maneira como as rubricas são discriminadas dificulta a avaliação das ações quanto a seus resultados e seus custos, ou seja, com relação à eficácia e à eficiência dos gastos, respectivamente ${ }^{45}$. Contudo, como evidenciam os números aqui apresentados, salienta-se que boa parte dos gastos federais direcionados ao meio rural é comprometido com benefícios previdenciários rurais e, fora isso, com a própria manutenção da máquina pública ${ }^{46}$. Além disso, vale refletir que o agronegócio de ponta, dinâmico e tecnologicamente avançado, deve depender cada vez menos de ações governamentais, exceto no que tange às condições de escoamento de sua produção e ações estratégicas, como defesa e inteligência territorial.

\section{CONCLUSÃO}

O presente texto procurou investigar como o governo federal, no horizonte de 2000 a 2017, alocou recursos do orçamento ao meio rural brasileiro. Para tanto, foram coletadas informações do Painel do Orçamento Federal (Brasil, 2018a) referentes à composição dos gastos anuais liquidados, segundo grupos de despesa e função, efetuando-se a correção dos valores para preços de dezembro de 2017, com o intuito de melhor analisar sua dinâmica.

A princípio, ressalta-se que os gastos federais cresceram, no período analisado, à taxa real de 0,10\% a.a. Essa variação, apesar de relativamente inexpressiva, significou um aumento real no montante de $\mathrm{R} \$ 705,5$ bilhões, dos quais o principal contribuinte se referiu à função de Previdência Social, que cresceu $\mathrm{R} \$ 382,7$ bilhões. Em menor grau, ainda se destacaram os aumentos absolutos nas funções de Educação, Cultura, Ciência/Tecnologia e Desporto/Lazer (R\$73,9 bilhões), Assistência Social e Direitos da Cidadania ( $R \$ 71,4$ bilhões), Trabalho (R\$51,7 bilhões), Saúde ( $R$ \$ 44,1 bilhões), Defesa Nacional ( $R \$ 32,6$ bilhões), Encargos Especiais ( $R \$ 22,5$ bilhões) e Judiciário e Essencial à

\footnotetext{
${ }^{43}$ Isso fica ainda mais aparente ao comparar o percentual com outros países no mesmo ano: 1,7\% na Rússia, 6,5\% na Índia, 2,4\% na China, 1,4\% na África do Sul, 1,7\% no México, 1,6\% no Chile e 2,5\% no Paraguai, por exemplo. Infelizmente, a Food and Agriculture Organization of the United Nations (2018a) não traz esses dados para alguns países, dificultando confrontar com a média da América Latina, por exemplo. Além disso, ressalta-se que essa medida não é propriamente adequada para comparação, visto que a Food and Agriculture Organization of the United Nations (2018a) não deduz do orçamento os gastos com a dívida pública.

${ }^{44}$ Esse segundo objetivo diz respeito a políticas de combate à fome, alcance da segurança alimentar, melhoria da nutrição e promoção da agricultura sustentável (United Nations, 2015).

${ }^{45}$ Mesmo que se deva reconhecer os avanços no acesso a dados fiscais, ainda há espaço para muitas melhorias na apresentação dessas informações. Para reforçar isso, vale observar que a falta de transparência nas contas públicas deve afetar a eficiência e a qualidade do gasto público, no sentido de que a "ilusão fiscal facilita o gasto improdutivo e as atividades de rent-seeking" (Araujo \& Siqueira, 2014, p. 20).

${ }^{46}$ Quanto aos benefícios previdenciários rurais, como mostra a Tabela 2, seu volume alcançou R $\$ 117,4$ bilhões em 2017. Por sua vez, ao se considerar o agregado $(d+f)$, também na Tabela 2 , do total de $R \$ 19,7$ bilhões especificamente direcionados ao meio rural em 2017, aproximadamente metade dizia respeito somente à manutenção da máquina pública, sobretudo pagamento de pessoal ativo e inativo, que somou $\mathrm{R} \$ 6,1$ bilhões naquele ano.
} 
Justiça ( $R \$ 19,5$ bilhões). As demais funções somaram um aumento real absoluto de apenas $R \$ 7,2$ bilhões.

Nesse contexto, só cinco funções registraram queda real no período: Comunicação ( $R \$ 0,01$ bilhão a menos), Gestão Ambiental (queda de $R \$ 0,22$ bilhão), Agricultura e Organização Agrária ( $R \$ 0,72$ bilhão), Urbanismo, Habitação, Saneamento e Transporte ( $R \$ 1,74$ bilhão) e Indústria, Comércio e Serviços ( $R \$ 2,10$ bilhões). Em termos relativos, por sua vez, a função de Agricultura e Organização Agrária (com -0,24\% a.a.) só ficou à frente das quedas registradas nas áreas de Gestão Ambiental (-0,40\% a.a.), Urbanismo, Habitação, Saneamento e Transporte (-0,71\% a.a.) e Indústria, Comércio e Serviços (-2,33\% a.a.).

Não bastasse a perda relativa de espaço na distribuição dos recursos, os gastos nas funções de Agricultura e Organização Rural ( $R \$ 17,3$ bilhões em 2017) ainda apresentaram desigualdades relativas às suas próprias ações. Por exemplo, créditos à cafeicultura cresceram consistentemente, com $R \$ 3,34$ bilhões em 2017, chegando a superar a parte do orçamento dedicada ao PRONAF ( $R \$ 2,11$ bilhões) ou a outros créditos voltados ao meio rural ( $R \$ 2,34$ bilhões). Enquanto isso, os gastos em ações de assistência técnica e extensão rural, pesquisa, desenvolvimento e inovação, e defesa agropecuária exibiram comportamento de queda, alcançando pouco mais de $\mathrm{R} \$ 0,5$ bilhão em 2017. Outra evidência da má distribuição foram os parcos recursos para a infraestrutura, como em importantes perímetros irrigados, que também apresentaram significativos recuos, não chegando a $R \$ 0,25$ bilhão em 2017 . Em contrapartida, os gastos com pessoal e encargos sociais ( $R \$ 6,12$ bilhões em 2017), somados a gastos administrativos nos órgãos federais relacionados à Agricultura e à Organização Agrária, cresceram para um volume acima do patamar dos $\mathrm{R} \$ 7$ bilhões, no mesmo ano.

Desde o ano 2000, evidencia-se que as funções de Agricultura e Organização Agrária têm perdido espaço na distribuição de recursos do orçamento federal. Como descrito, esse processo se acentuou, sobretudo, desde 2007, coincidindo, inclusive, com a forte seca que assolou o Nordeste entre 2011 e 2017, época em que seria fundamental uma maior atuação do governo federal ${ }^{47}$. Ainda, destaca-se que, com a vigência da Emenda Constitucional no 95 , de 15 de dezembro de 2016 (Brasil, 2016), a qual limita o crescimento dos gastos públicos até o ano de $2036^{48}$, avançará a concorrência das funções pela utilização desses recursos ${ }^{49}$. Seguindo a tendência do que ocorreu no horizonte de tempo analisado; portanto, é preciso enfatizar a relevância das funções de Agricultura e Organização Agrária e buscar a reversão desse comportamento de perda relativa verificada em seus recursos aplicados ${ }^{50}$.

Agregando-se os gastos associados ao meio rural, mas não identificados com as funções de Agricultura e Organização Agrária, verificou-se ainda que a Previdência Social voltada a beneficiários rurais foi a principal responsável pela aplicação de recursos públicos nesse meio, com R\$117,4 bilhões em 2017. Quanto a outras funções, os gastos relacionados com o meio rural somaram outros $R \$ 2,4$ bilhões no mesmo ano, sobretudo em transferências do Imposto Territorial Rural e programas como PROAGRO e PAA. Agregando-se esses gastos, calcula-se que, em 2017, apenas 9,02\% do orçamento público federal foi direcionado ao meio rural ${ }^{51}$. Se os gastos na função de Previdência Social forem desconsiderados do cálculo, o

\footnotetext{
${ }^{47}$ Como colocado na Introdução, a análise infelizmente contém um grau de agregação que não permite avaliar a distribuição geográfica das aplicações.

${ }^{48} \mathrm{~A}$ medida foi aprovada com o intuito de estabelecer regras que possibilitassem a sustentabilidade das contas públicas e a gradual obtenção de superávits primários.

${ }^{49}$ Enfatiza-se que os gastos públicos são definidos pela Lei Orçamentária Anual (LOA), norteada por prioridades definidas na Lei de Diretrizes Orçamentárias (LDO), a qual se baseia no Plano Plurianual (PPA). Os três textos (PPA, LDO e LOA) são propostos pelo Executivo e seguem para análise, ajuste e aprovação pelo Legislativo, de forma que a prioridade relativa de cada item do orçamento envolve decisões políticas.

${ }^{50}$ Nesse aspecto, é relevante a discussão sobre as alternativas para ampliar o montante de tais aplicações, sendo essencial a realização de reformas sobre temas como arrecadação de recursos, aplicação eficiente em todos os grupos de gasto (punindo-se desvios de forma eficaz), Previdência Social (restrição a privilégios, protegendo-se os menos favorecidos), apenas para citar alguns exemplos.

${ }^{51}$ Esse percentual desconsidera, no denominador, os gastos nos grupos de Amortização, Juros e Encargos da Dívida. Considerando-se esses grupos no orçamento geral, esse percentual cai para apenas 5,47\%.
} 
percentual destinado ao meio rural correspondeu a um tímido percentual de $2,28 \%{ }^{52}$. Tais resultados reforçam a ideia de que é necessário ressaltar a importância do meio rural e pleitear mais recursos para seu desenvolvimento, o que deve ser combinado a uma melhor distribuição desses gastos, prezando por sua aplicação eficiente.

Com efeito, para a média do ano de 2017, o meio rural representou quase $10 \%$ da população ocupada no país (Instituto Brasileiro de Geografia e Estatística, 2018). Cálculos do Centro de Estudos Avançados em Economia Aplicada (CEPEA) apontam que o agronegócio representou 21,3\% do PIB brasileiro em 2017. Ainda, em 2015, o meio rural abrigava 15,3\% da população brasileira (Universidade de São Paulo, 2018; Instituto Brasileiro de Geografia e Estatística, 2018). No Nordeste, por exemplo, essa participação chegou a alcançar uma proporção de 26,9\% no mesmo ano (Instituto Brasileiro de Geografia e Estatística, 2018). Trata-se, portanto, do lar e do meio de vida para expressiva parcela de eleitores deste país. Infelizmente, a coordenação de forças nesse meio parece menos articulada que a observada no meio urbano, a ponto de não competir eficazmente por uma maior fatia de recursos, a ser utilizada de maneira racional, ao menos para reparar as perdas ocorridas nos últimos anos. Trata-se de recursos essenciais para pesquisa, difusão de tecnologias e conhecimentos, apoio à produção e à logística, adensamento de cadeias produtivas, coordenação para acesso a mercados, financiamento de negócios, auxílio no custeio de atividades, entre outros incentivos. Do contrário, a não reversão da tendência de queda relativa dos gastos públicos no setor apenas contribuiria para o agravamento de um meio rural em processo de esvaziamento e pouco atrativo, sobretudo aos que vivem em áreas menos dinâmicas.

\section{REFERÊNCIAS}

Abreu, T. F. R., \& Lima, E. C. R. (2018). A eficácia da política fiscal no Brasil: uma abordagem SVAR identificado com restrições de sinais e de zeros. In Anais do $46^{\circ}$ Encontro Nacional de Economia. Rio de Janeiro: ANPEC.

Araujo, J. M., \& Siqueira, R. S. (2014). Demanda por gastos públicos locais: evidências dos efeitos de ilusão fiscal no Brasil. In Anais do $42^{\circ}$ Encontro Nacional de Economia. Natal: ANPEC.

Banco Central do Brasil - BCB. (2018). Sistema financeiro nacional. Recuperado em 1 de outubro de 2018, de bit.do/fGoJY

Banco Nacional de Desenvolvimento Econômico e Social - BNDES. (2018). Central de downloads. Brasília. Recuperado em 1 de outubro de 2018, de bit.do/fGoLs

Brasil. Ministério do Planejamento, Secretaria de Orçamento Federal. (2018a). Painel do orçamento federal. Brasília. Recuperado em 1 de outubro de 2018, de bit.do/fGoM2

Brasil. Ministério do Planejamento. Secretaria de Orçamento Federal. (2018b). Introdução ao SIOP. Brasília. Recuperado em 1 de outubro de 2018, de bit.do/fGoLV

Brasil. Ministério do Planejamento. Secretaria de Orçamento Federal. (2018c). Manual técnico de orçamento. Brasília. Recuperado em 1 de outubro de 2018, de bit.do/fGoMw

Brasil. Ministério da Integração. Secretaria de Fundos Regionais e Incentivos Fiscais. (2018d). Publicações. Brasília. Recuperado em 1 de outubro de 2018, de bit.do/fGoLb

Brasil. Presidência da República. (2016, dezembro 15). Emenda Constitucional n 95, de 15 de dezembro de 2016. Altera o Ato das Disposições Constitucionais Transitórias [...]. Diário Oficial [da] República Federativa do Brasil, Brasília. Recuperado em 1 de outubro de 2018, de bit.do/fGoNo

Food and Agriculture Organization of the United Nations - FAO. (2018a). FAOStat. Rome. Recuperado em 1 de outubro de 2018, de from bit.do/fGoNR

Food and Agriculture Organization of the United Nations - FAO. (2018b). Sustainable development goals: indicator 2.a.1. Rome. Recuperado em 1 de outubro de 2018, de bit.do/fGoPc

Giambiagi, F., Pinto, F., \& Rothmuller, L. (2018). Reforma previdenciária em 2019: elementos para uma tomada de decisão (Texto para Discussão, No. 127). Rio de Janeiro: BNDES.

\footnotetext{
${ }^{52} \mathrm{Na}$ melhor das hipóteses, considerando que os gastos não relacionados especificamente com o meio rural ainda beneficiam sua população, na proporção de seus habitantes relativa à população brasileira, $17,51 \%$ do orçamento geral seria destinado ao meio rural, incluindo os valores alocados para benefícios previdenciários rurais. Esse percentual exclui do orçamento geral os gastos em Amortização, Juros e Encargos da Dívida, mas, ao incluir tais grupos, a parcela se situaria em 10,62\%. Assim mesmo, trata-se de uma hipótese bastante otimista.
} 
Gobetti, S. W., Orair, R. O. (2017). Resultado primário e contabilidade criativa: reconstruindo as estatísticas fiscais "acima da linha" do governo geral (Texto para Discussão, No. 88). Rio de Janeiro: BNDES.

Guedes, S. N. R., \& Fleury, R. R. (2016). Reforma agrária e concentração fundiária: uma análise de 25 anos de reforma agrária no Brasil. Revista Economica do Nordeste, 47(3), 31-44.

Instituto Brasileiro de Geografia e Estatística - IBGE. (2018). Sistema IBGE de recuperação automática. Recuperado em 1 de outubro de 2018, de bit.do/fGoJD

Orair, R. O. (2014). A dinâmica recente dos gastos públicos brasileiros (III): a retomada do investimento público no Brasil e os desafios do padrão de financiamento. In C. H. M. Santos \& R. R. Gouvêa (Eds.), Finanças públicas e macroeconomia no Brasil: um registro da reflexão do Ipea (2008-2014) (Vol. 2, pp. 89-110). Brasília: IPEA.

Santos, G. R., \& Freitas, R. E. (2017). Gasto público com a agricultura no Brasil: uma abordagem a partir de dados agregados (Boletim Regional, Urbano e Ambiental, No. 17, pp. 89-98). Brasília: IPEA.

United Nations - UN. (2015, October 21). Resolution 70/1 adopted by General Assembly on 25 september 2015. Transforming our world: the 2030 Agenda for Sustainable Development. General Assembly, New York.

Universidade de São Paulo - USP. Escola Superior de Agricultura "Luiz de Queiroz", Centro de Estudos Avançados em Economia Aplicada - CEPEA. (2018). PIB do agronegócio brasileiro. Piracicaba. Recuperado em 1 de outubro de 2018, de bit.do/fGoNE. 